\title{
A Phenomenological Paradigm for Midtropospheric Cyclogenesis in the Indian Summer Monsoon 0
}

\author{
Ayantika Dey Choudhury, R. Krishnan, M. V. S. Ramarao, R. Vellore, and M. Singh \\ Centre for Climate Change Research, Indian Institute of Tropical Meteorology, Pune, India
}

\author{
B. MAPES
}

Rosenstiel School of Marine and Atmospheric Science, University of Miami, Miami, Florida

(Manuscript received 8 December 2017, in final form 22 May 2018)

\begin{abstract}
Midtropospheric cyclones (MTCs) are a distinct class of synoptic disturbances, characterized by quasistationary cyclonic circulation in midtropospheric levels, which often produce heavy rainfall and floods over western India during the summer monsoon. This study presents a composite and diagnostic process study of long-lived ( $>5$ days) midtropospheric cyclonic circulation events identified by the India Meteorological Department (IMD). Reanalysis data confirm earlier studies in revealing that the MTC composite has its strongest circulation in the midtroposphere. Lagged composites show that these events co-occur with broader-scale monsoon evolution, including larger synoptic-scale low pressure systems over the Bay of Bengal $(\mathrm{BoB})$ and east coast, and the active phase of regional-scale poleward-propagating intraseasonal rain belts, with associated drying ahead (north) of the convectively active area. Diabatic heating composites, in particular the TRMM latent heating and Modern-Era Retrospective Analysis for Research and Applications, version 2 (MERRA-2)-derived radiative cooling in the dry inland areas of southwest Asia north of the rain belt, are used to drive a nonlinear multilayer dynamical model in a forced-damped reconstruction of the global circulation. Results show that the midlevel circulation is largely attributable to top-heavy latent heating, indicative of the prevalence of stratiform-type precipitation in mesoscale convective systems in these moist, active larger-scale settings. Both the west coast and BoB latent heating are important, while the radiative cooling over southwest Asia plays a modest role in sharpening some of the simulated features. A conceptual model encapsulates the paradigm based on this composite and diagnostic modeling, a diabatic update of early theoretical studies that emphasized hydrodynamic flow instabilities.
\end{abstract}

\section{Introduction}

Midtropospheric cyclones (MTCs) constitute a distinct class of quasi-stationary synoptic-scale disturbances during the boreal summer monsoon season. They form over the northeastern Arabian Sea around the Indian state of Gujarat (Miller and Keshavamurthy 1968, hereafter MK68; also see Fig. 1) and occasionally over the southern Indo-China/Southeast Asia region (Krishnamurti and Hawkins 1970), making them broadly regional phenomena. However, the MTCs of

\footnotetext{
Supplemental information related to this paper is available at the Journals Online website: https://doi.org/10.1175/JAS-D-170356.s1.
}

Corresponding author: R. Krishnan, krish@tropmet.res.in the northeastern Arabian Sea have received special attention in the past in view of their important role in activating heavy rainfall along the west coast of India near Gujarat, leading to heavy flooding and damage in the region (e.g., MK68; Carr 1977; Jayanthi et al. 2006; Routray et al. 2010). Based on analyses of observations from the International Indian Ocean Experiment (IIOE), MK68 presented a comprehensive monograph on the circulation features associated with the seminal MTC that occurred during 2-10 July 1963. Observational evidence from the aforementioned studies reveal that MTCs are characterized by a cyclonic vortex with maximum relative vorticity seen at midtropospheric levels $(700-500 \mathrm{hPa})$ and without much coexisting surface signatures. Typically, the spatial scale of the disturbance is about $1000 \mathrm{~km}$ in the horizontal, with a vertical extent of $6-8 \mathrm{~km}$. The disturbance is known to 

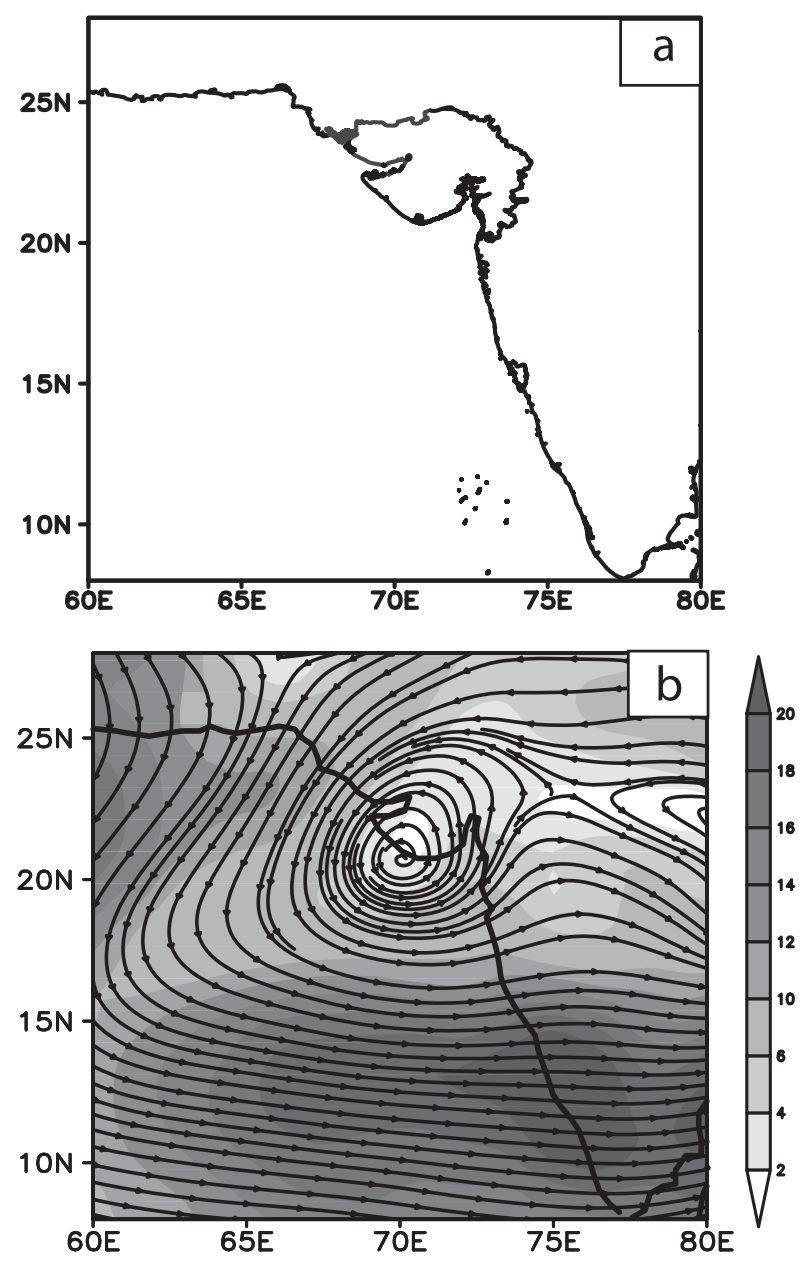

FIG. 1. (a) Boundary showing the Indian state of Gujarat. (b) The 600-hPa streamline and wind speed (shading) for $31 \mathrm{Jul}-7$ Aug 2007 MTC based on ERA-Interim data. Wind speed is given in knots $\left(\mathrm{kt} ; 1 \mathrm{kt}=0.51 \mathrm{~m} \mathrm{~s}^{-1}\right)$.

exhibit strong midlevel convergence and upward vertical velocities, with the temperature field portraying cold (warm) anomalies below (above) $500 \mathrm{hPa}$ in association with the release of latent heat by precipitating clouds. The reader is referred to MK68, Krishnamurti and Hawkins (1970), and Carr (1977) for further literature on the observed aspects of MTCs.

Theoretical studies have investigated the genesis and intensification mechanisms of the Indian summer monsoon MTCs. Ramage (1966) hypothesized that an intensification of monsoon heat low by thermodynamical processes over the west Asian subtropical region, covering the Arabian Peninsula, Iran, Afghanistan, and Pakistan, can potentially export cyclonic vorticity toward western India, giving way to subtropical cyclogenesis over the east Arabian Sea in the presence of a moisture-laden westerly flow. Subsequent studies by
Krishnamurti and Hawkins (1970) and Carr (1977) highlighted the importance of latent heating from cumulus-scale convection in maintaining midlevel circulation and warm core in the upper troposphere. Mak (1975) suggested that MTCs can be generated through a special class of baroclinic instability in the South Asian monsoon environment, in which the east-west temperature gradient between the Bay of Bengal and Arabian Sea at different heights can give rise to vertical shear in the meridional winds to support the growth of MTCs. Further extension to this theoretical work suggested that condensational heating is important in the formative stages of the MTC, while the combined effects of baroclinic flow and condensational heating result in the large growth rate of MTCs (Mak 1983). A caveat in the simplified theoretical model of Mak $(1975,1983)$ is, however, the requirement of an unrealistically large vertical shear of the meridional wind in order to capture the observed structure of MTCs (Brode and Mak 1978). Further, the level of maximum intensity of the cyclonic anomaly in Mak's model calculation occurs at a much lower level, and the maximum vertical velocity is displaced significantly westward as compared to observations (MK68). While there have been only a few studies on the northeastern Arabian Sea MTCs in recent times (e.g., Jayanthi et al. 2006; Routray et al. 2010), the importance of midlevel circulation and elevated maximum of potential vorticity has been mostly emphasized in the context of the Bay of Bengal low pressure systems and monsoon depressions (e.g., Boos et al. 2015, 2017; Hurley and Boos 2015; Hunt et al. 2016).

While taking cognizance of the aforementioned studies, a phenomenological understanding of the basic mechanisms behind genesis of the Indian monsoon MTCs has not been adequately explored. Past studies have extensively documented slow northward propagation of organized convection bands from the equatorial Indian Ocean into the Indian subcontinent at a latitudinal speed of approximately $1^{\circ} \mathrm{day}^{-1}$ associated with the boreal summer monsoon intraseasonal oscillation (ISO) and their influence on the active and break monsoon spells over India (e.g., Yasunari 1979, 1980; Sikka and Gadgil 1980; Krishnamurti and Subrahmanyam 1982; Hartmann and Michelsen 1989; Singh et al. 1992; Krishnan et al. 2000; Krishnamurthy and Shukla 2000; Goswami 2005; Wang 2005). It is also acknowledged that MTCs over the northeast Arabian Sea can undergo intensification in the presence of westward-propagating monsoon depressions and low pressure systems from the Bay of Bengal (MK68; Carr 1977).

The prevalence of precipitating mesoscale convective systems (MCSs) in the convective envelope of monsoon 
intraseasonal variability is an important element of the Indian summer monsoon (Virts and Houze 2016). Tropical and monsoon MCSs show a predominance of stratiform-type precipitation largely from nimbostratus clouds, along with embedded deep convective cells, which provide an important connection between organized monsoon convection and circulation through release of latent heat of condensation (e.g., Mapes 1993; Mapes and Houze 1995; Houze 1997; Stano et al. 2002; Krishnan et al. 2011; Romatschke and Houze 2011). The availability of observed precipitation profiles from the Tropical Rainfall Measuring Mission (TRMM) Precipitation Radar (PR) has provided an extraordinary opportunity to comprehensively describe the vertical structure and three-dimensional spatial distribution of latent heating associated with organized tropical convection (e.g., Tao et al. 2001, 2010; Houze 2004; Shige et al. 2004; Shige and Kummerow 2016), and how they influence large-scale circulation over the tropics and monsoon regions (e.g., Hartmann et al. 1984; Schumacher et al. 2004; Choudhury and Krishnan 2011). Studies have demonstrated that large populations of stratiform-type precipitation, characterized by top-heavy heating with maximum amplitude around $400 \mathrm{hPa}$, are crucial for the intensification of midlevel cyclonic circulation response and also favor the northward propagation of organized convection during the Indian summer monsoon (Chattopadhyay et al. 2009; Choudhury and Krishnan 2011; Kumar and Krishnamurti 2016).

With this background, there are still some motivating open questions; namely, Is there a possible linkage between development of MTC over northeastern Arabian Sea and northward propagation of organized summer monsoon convection on subseasonal time scales? What is the role of latent heating from organized precipitating systems in MTCs over the northeastern Arabian Sea? What is the thermodynamic influence of the west Asian subtropical high variability (Ramage 1966) on midtropospheric cyclogenesis over the northeastern Arabian Sea? With these questions in view, this study undertakes a phenomenological approach to understand the dynamical and physical mechanisms associated with midtropospheric cyclogenesis over the northeastern Arabian Sea during the Indian summer monsoon using diagnostic analysis of observational data products together with sensitivity experiments using a simple general circulation model.

\section{Datasets and model details}

Datasets used in this study include three-dimensional gridded atmospheric fields (archived on pressure levels at $1.5^{\circ} \times 1.5^{\circ}$ grid resolution in the horizontal) from the ECMWF interim reanalysis (ERA-Interim; Dee and Uppala 2009; Dee et al. 2011) products for the period 1979-2010. Radiative cooling data for the period 19802010 are obtained from the Modern-Era Retrospective Analysis for Research and Applications, version 2 (MERRA-2) (Bosilovich et al. 2015). Precipitation data from various sources have been utilized for the study. These include India Meteorological Department (IMD) $0.25^{\circ} \times 0.25^{\circ}$ gridded rainfall (Pai et al. 2015), TRMM daily $3 \mathrm{~B} 42$, version $7\left(\mathrm{~V} 7 ; 0.25^{\circ} \times 0.25^{\circ}\right.$ resolution; Huffman et al. 1997, 2007), and TRMM monthly 3A25 rainfall estimates. The analysis also employs gridded orbital 3G31 V7 convective-stratiform heating (CSH) rates (Tao et al. 2010) generated from the TRMM PR/TMI observations and monthly 3H25 V7 spectral latent heating (Shige et al. 2004, 2007, 2009) derived using PR observations. The outgoing longwave radiation (OLR) data have been obtained from the National Oceanic and Atmospheric Administration (NOAA) for the period 1981-2010.

The numerical simulations in this study are conducted using a global atmospheric general circulation model (GCM) dynamical core based on the spectral formulation of Bourke (1974). We have used a rhomboidal truncation at zonal wavenumber 40 (R40), which approximately corresponds to a Gaussian grid with horizontal resolution of $2.835^{\circ}$ (longitude) $\times 1.76^{\circ}$ (latitude) . The model has 25 vertical levels (L25) following the normalized pressure coordinates in the vertical, that is, $\sigma$ coordinates $\left(\sigma=p / p_{s}\right.$, where $p$ is air pressure and $p_{s}$ is surface pressure). The R40L25 GCM has been earlier employed to understand the circulation dynamics and variability of the Indian summer monsoon, and further details are available in Sundaram et al. (2010) and Choudhury and Krishnan (2011). The GCM is a dry model forced by prescribed heating balanced by damping terms (Rayleigh friction and Newtonian cooling) in the momentum and thermodynamic equations (Choudhury and Krishnan 2011). Using this model, we conduct six sets of GCM experiments: control (CTRL), Arabian Sea (AS), AS radiative cooling (ASRC), AS RC Bay of Bengal (ASRCBB), and two additional versions of ASRC. Basically, the experiments differ in terms of the imposed latent heating and radiative cooling, and the acronyms of the experiments are briefly explained below. In the CTRL experiment, the model is forced with the climatological mean summer monsoon latent heating. The sensitivity experiment AS includes the effect of anomalous latent heating associated with increased activity of the MCS over the Arabian Sea and adjoining land regions, which is superposed on the climatological mean heating. The ASRC sensitivity 

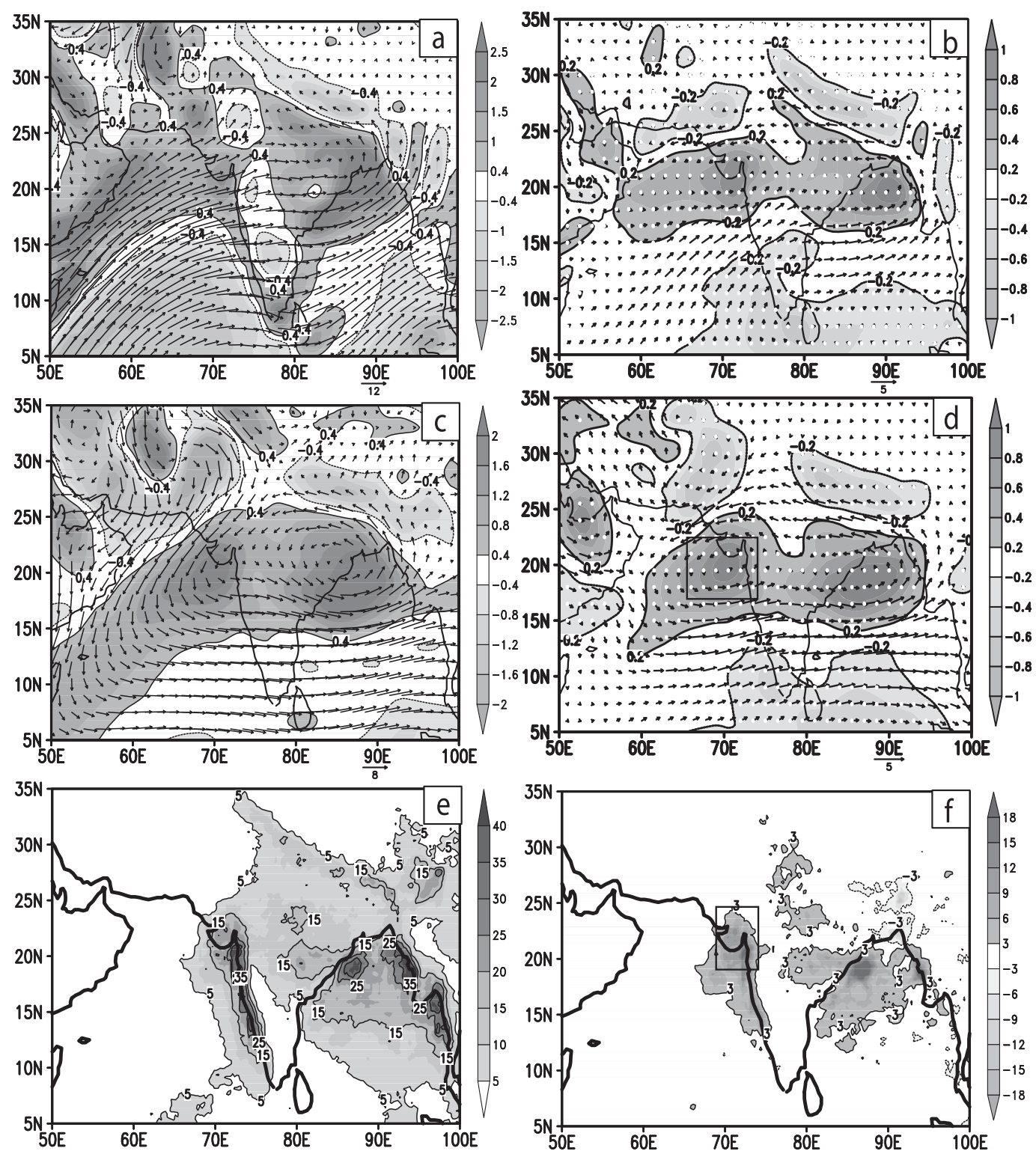

FIG. 2. Composite maps based on all the MTC events, during the boreal summer monsoon (June-September), selected for this study. Low-level $\left(1000-850 \mathrm{hPa}\right.$ ) wind (arrows; $\mathrm{m} \mathrm{s}^{-1}$ ) and relative vorticity (shading; $\times 10^{-5} \mathrm{~s}^{-1}$ ) for (a) total field and (b) anomalous field; (c),(d) As in (a) and (b), respectively, but for midtropospheric levels (650$500 \mathrm{hPa}$ ). The white dots in (b) and (d) denote regions over which the relative vorticity anomaly is statistically significant at $5 \%$ level; (e),(f) As in (a) and (b), respectively, but for rainfall $\left(\mathrm{mm} \mathrm{day}^{-1}\right)$. The boxes in (d) and (f) show the regions considered for selection criterion of MTC using circulation features and rainfall, respectively. The data are based on ERA-Interim.

experiment includes the effects of the AS latent heating plus intense radiative cooling over west Asia. The ASRCBB considers the effects of MCS latent heating over the AS and radiative cooling over west Asia, as well as the latent heating due to westwardpropagating MCS from the Bay of Bengal. The design of the control and sensitivity experiments are explained in section 3 a.

\section{Data diagnostics}

\section{a. Identification of MTC events}

The selection of MTC events for this study, during the period 1988-2008, involves the following procedure:

(i) The first step involves identification of MTC events using weather reports prepared by the IMD based on synoptic charts derived from surface and 
TABLE 1. Dates of midtropospheric circulations from IMD weather summaries for the period 1988-2007 and associated precipitation accumulations over western India $\left(17^{\circ}-23^{\circ} \mathrm{N}, 68^{\circ}-74^{\circ} \mathrm{E}\right)$. The check marking in column 5 indicate that the MTC was selected for the present analysis.

\begin{tabular}{|c|c|c|c|c|}
\hline No. & MTC case & No. of days & $\begin{array}{c}\text { Mean rainfall } \\
\text { accumulation }(\mathrm{cm})\end{array}$ & MTC selection \\
\hline 1 & 15-22 Aug 1988 & 8 & 25 & $\checkmark$ \\
\hline 2 & 20-25 Aug 1989 & 5 & 33 & $\checkmark$ \\
\hline 3 & 11-15 Sep 1989 & 5 & 4 & \\
\hline 4 & 26-30 Jun 1990 & 5 & 44 & $\checkmark$ \\
\hline 5 & 13-22 Aug 1991 & 10 & 21 & \\
\hline 6 & 18-25 Jul 1992 & 8 & 58 & $\checkmark$ \\
\hline 7 & 18-29 Aug 1993 & 12 & 10 & \\
\hline 8 & 22-30 Aug 1994 & 9 & 46 & $\checkmark$ \\
\hline 9 & 14-22 Sep 1994 & 9 & 5 & \\
\hline 10 & 4-8 Jul 1995 & 5 & 4 & \\
\hline 11 & 11-23 Jul 1995 & 13 & 70 & $\checkmark$ \\
\hline 12 & 10-20 Aug 1995 & 11 & 6 & \\
\hline 13 & 6-11 Sep 1995 & 6 & 5 & \\
\hline 14 & 20-24 Jul 1996 & 5 & 91 & $\checkmark$ \\
\hline 15 & 4-9 Jul 1997 & 6 & 44 & $\checkmark$ \\
\hline 16 & 6-11 Sep 1997 & 6 & 19 & \\
\hline 17 & 30 Aug-4 Sep 1998 & 6 & 9 & \\
\hline 18 & 4-8 Aug 1999 & 5 & 27 & $\checkmark$ \\
\hline 19 & 2-6 Sep 1999 & 5 & 9 & \\
\hline 20 & 27 Jun-15 Jul 2000 & 19 & 57 & $\checkmark$ \\
\hline 21 & 18-24 Aug 2000 & 7 & 22 & \\
\hline 22 & 6-11 Aug 2002 & 6 & 55 & $\checkmark$ \\
\hline 23 & 18-27 Sep 2002 & 10 & 3 & \\
\hline 24 & $1-8 \mathrm{Jul} 2003$ & 8 & 41 & $\checkmark$ \\
\hline 25 & 12-19 Jul 2003 & 8 & 40 & $\checkmark$ \\
\hline 26 & 1-13 Aug 2003 & 13 & 34 & $\checkmark$ \\
\hline 27 & 13-26 Sep 2003 & 14 & 12 & \\
\hline 28 & 29 Jun-8 Jul 2004 & 10 & 28 & $\checkmark$ \\
\hline 29 & 12-19 Sep 2004 & 8 & 5 & \\
\hline 30 & 24 Jun-3 Jul 2005 & 10 & 150 & $\checkmark$ \\
\hline 31 & 23 Aug-1 Sep 2005 & 10 & 7 & \\
\hline 32 & 28 Jun-4 Jul 2006 & 7 & 83 & $\checkmark$ \\
\hline 33 & 31 Jul-7 Aug 2007 & 8 & 91 & $\checkmark$ \\
\hline 34 & 27 Jul-5 Aug 2008 & 10 & 54 & $\checkmark$ \\
\hline 35 & 12-18 Sep 2008 & 7 & 72 & $\checkmark$ \\
\hline
\end{tabular}

upper-air sounding observations. Information about dates, locations, synoptic-scale weather conditions, and durations of midtropospheric cyclonic circulation are contained in the IMD reports, which are documented in the seasonal weather summaries published every year (e.g., Mazumdar et al. 2007, 2008, 2009). For this study, we have focused on midtropospheric cyclonic circulations that lasted for 5 days or more over the west coast of India around the region of Gujarat $\left(17^{\circ}-23^{\circ} \mathrm{N}, 65^{\circ}-74^{\circ} \mathrm{E}\right.$; box shown in Fig. 2d). This identification process yielded 35 cases of MTC occurrences with duration $\geq 5$ days, and these cases actually serve as guidance for objective determination of MTC events.

(ii) Since the interest of this study is on heavy precipitation events co-occurring with MTCs, we apply an objective criterion that the observed mean rainfall accumulation over western India $\left(17^{\circ}-23^{\circ} \mathrm{N}\right.$, $68^{\circ}-74^{\circ} \mathrm{E}$ ) during the duration of the MTC exceeds a critical value of $25 \mathrm{~cm}$. The mean rainfall accumulation is the temporal average of daily rainfall accumulations during the duration of the MTC event. This representative threshold is based on earlier reports of heavy precipitation typically observed in the environment of MTCs (e.g., MK68; Routray et al. 2010) and is $25 \%$ above the climatological monsoon rainfall accumulation over the region. Using the high-resolution $\left(0.25^{\circ} \times 0.25^{\circ}\right)$ daily gridded IMD rainfall dataset, we noted that 20 MTC cases satisfy the above criterion. The IMD rainfall observations are only over the land points of India, and therefore, the westernmost longitude 
$\left(68^{\circ} \mathrm{E}\right)$ corresponds to the western boundary for the rainfall threshold calculations. Thus, the final selection resulted in 20 MTC cases that are used in our analyses (Table 1). In many places, these events are the heaviest-rain-producing weather in the region: For example, Table 2 shows that MTC cases correspond to several of the record rainfall events around the region of Gujarat in TRMM 3B42, as tabulated by Mapes (2011) and its update documented in Matilla and Mapes (2018). Further, it is noted that the daily maximum midtropospheric relative vorticity for the 20 selected MTC cases is in the range from $2 \times 10^{-5}$ to $11 \times 10^{-5} \mathrm{~s}^{-1}$, which corroborates well with the typical relative vorticity maximum reported by MK68. The streamlines and wind speeds at $600 \mathrm{hPa}$ for a typical MTC event (31 July-7 August 2007) are shown in Fig. 1. Note that the synoptic-scale midtropospheric circulation and the mesoscale cyclonic vortex near Gujarat are similar to that reported by MK68.

\section{b. Spatial pattern of circulation and rainfall during MTC events}

Composite-mean characteristics of MTCs occurring during the southwest monsoon period (June-September), diagnosed from reanalyses and ground- and satellitebased observational datasets, are presented below. The composites are constructed by averaging the atmospheric fields over the MTC periods for all the selected cases shown in Table 1. Daily anomalies are computed with respect to the daily climatology of corresponding datasets. High-resolution daily rainfall data encompassing both land and oceanic regions became available with the launch of TRMM in 1998, and therefore, the rainfall composites are diagnosed for the period 19982008. However, the availability of circulation data over a longer period allows us to examine circulation composites for the period 1988-2008. We have also verified that composite maps of circulation for MTC cases during 1998-2008 are rather similar to those during 19882008 and do not alter the overall results.

Composite maps of mean and anomalous horizontal winds, relative vorticity, and rainfall are shown in Fig. 2. Notice the predominance of low-level southwesterly monsoon flow from the Arabian Sea into the Indian subcontinent. The monsoon flow is accompanied by a cyclonic vorticity maximum over the eastern edge of the monsoon trough near the northern Bay of Bengal (BoB; Fig. 2a). The midlevel $(650-500 \mathrm{hPa})$ circulation shows a large-scale cyclonic gyre across the Indian subcontinent with two distinct cyclonic vorticity maxima located over the northern Arabian Sea and BoB,
TABLE 2. Heaviest 3-day precipitation accumulations (exceeding $300 \mathrm{~mm}$ ) over western India during 1998-2007 identified from interactive web atlas (Mapes 2011). Also shown are the central locations, time, and date for the 3-day-period events.

\begin{tabular}{cccc}
\hline \hline Lat $\left({ }^{\circ} \mathrm{N}\right)$ & Lon $\left({ }^{\circ} \mathrm{E}\right)$ & $\begin{array}{c}\text { 3-day rainfall } \\
\text { accumulation }(\mathrm{mm})\end{array}$ & $\begin{array}{c}\text { Time and date } \\
\text { of event }\end{array}$ \\
\hline 20.87 & 72.7 & 700 & 1600 UTC 28 Jun 2005 \\
20.62 & 73.0 & 650 & 1600 UTC 28 Jun 2005 \\
22.12 & 73.5 & 550 & 0000 UTC 29 Jun 2005 \\
22.62 & 73.0 & 500 & 1800 UTC 30 Jun 2005 \\
19.62 & 71.5 & 350 & 2000 UTC 3 Jul 2006 \\
18.87 & 72.2 & 400 & 2000 UTC 3 Jul 2006 \\
21.87 & 73.5 & 450 & 0400 UTC 4 Jul 2006 \\
20.87 & 69.7 & 350 & 1800 UTC 5 Aug 2007 \\
20.37 & 70.5 & 400 & 1200 UTC 5 Aug 2007 \\
23.37 & 72.0 & 400 & 0400 UTC 7 Aug 2007 \\
\hline
\end{tabular}

respectively (Fig. 2c). This is consistent with observed midlevel cyclonic circulation features during MTC episodes over the northern Arabian Sea (MK68; Carr 1977). The continental-scale cyclonic gyre and the embedded vortex centers over the northern Arabian Sea and BoB are clearly evident in the circulation anomaly composites (Figs. 2b,d). Strong cyclonic vorticity $\left(\geq 10^{-4} \mathrm{~s}^{-1}\right)$ over the northern Arabian Sea is more prominent at the midlevels than at low levels. The presence of anomalous cyclonic vortex over the head of the BoB (Fig. 2d) indicates that the heavily precipitating MTCs co-occur quite regularly with depressions and low pressure systems (LPSs) over the BoB. From IMD data, we found that with the exception of only two cases, all selected heavily precipitating MTCs were accompanied by a westward-propagating LPS or depression. While confined regions with high rainfall $\left(\geq 15 \mathrm{~mm} \mathrm{day}^{-1}\right)$ are evident along the western part of India, moderate and widespread rainfall activity can be noted over central India and northern BoB (Fig. 2e).

\section{c. Space-time evolution of circulation and rainfall}

Figure 3 shows composites of daily evolution of anomalous midtropospheric winds and streamfunction for the MTC periods described in Table 1. Day 0 corresponds to the first day of the MTC composite as reported in the IMD weather summaries. Prior to onset of MTC (designated by days $-3,-2,-1$ ), one can notice a spatially extended cyclonic circulation anomaly over the Arabian Sea, peninsular India, and the southern BoB. The streamfunction minimum is seen over the northcentral Arabian Sea. An anticyclone at the nascent stage is also noticed over the west Asian region north of Afghanistan and Pakistan (Figs. 3a-c) during this time. Enhanced cyclonic anomalies on day 0 over the north 
(a) DAY (-3)

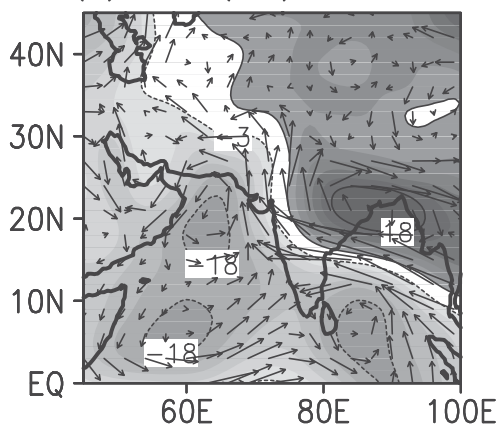

(d) DAY (0)

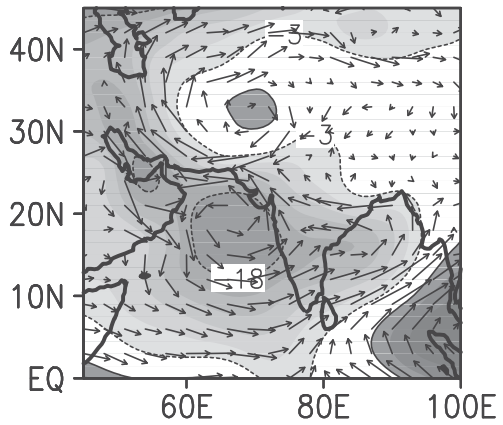

(g) DAY (3)

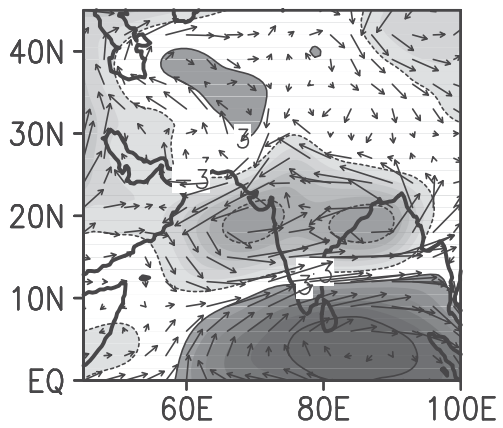

(j) DAY (6)

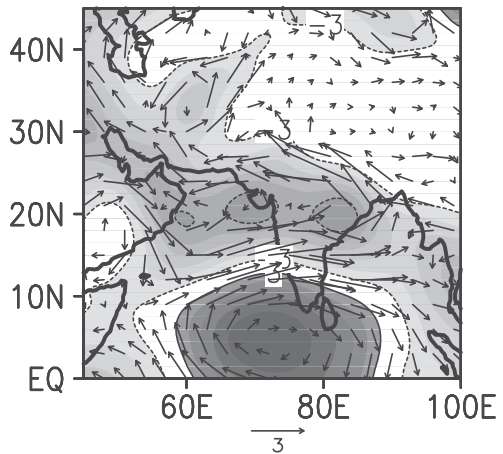

(b) DAY (-2)

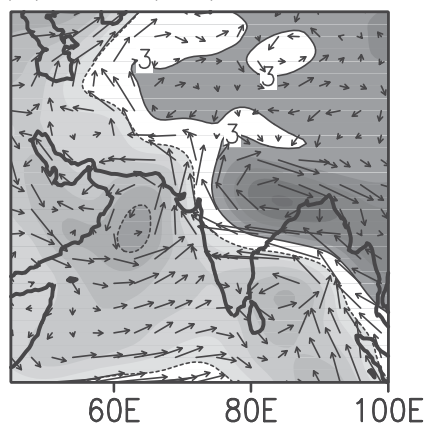

(e) DAY (1)

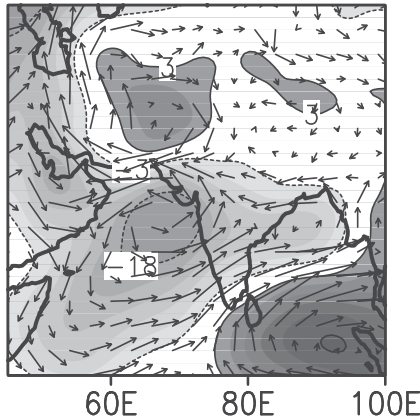

(h) DAY (4)

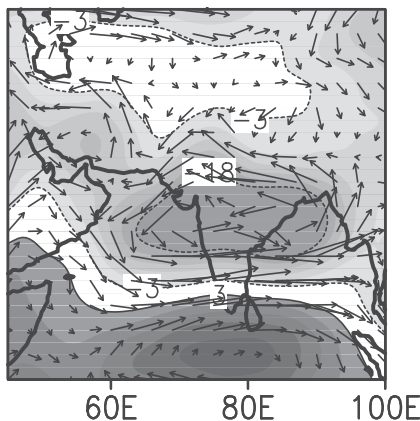

(k) DAY (7)

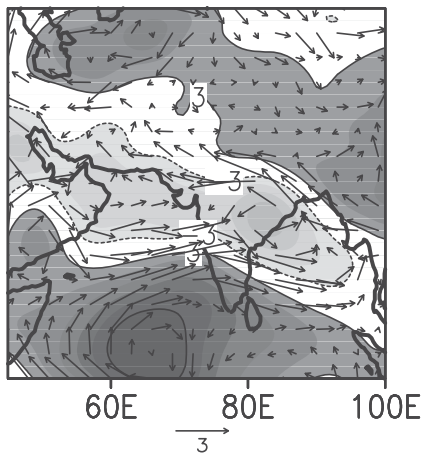

(c) DAY $(-1)$

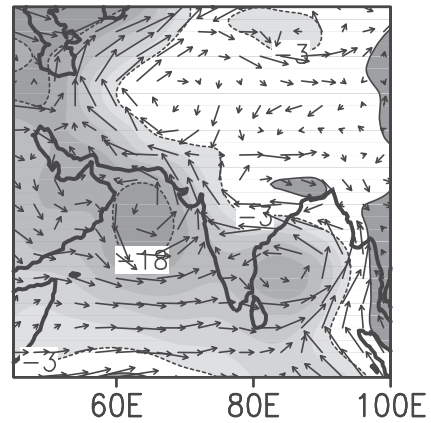

(f) DAY (2)

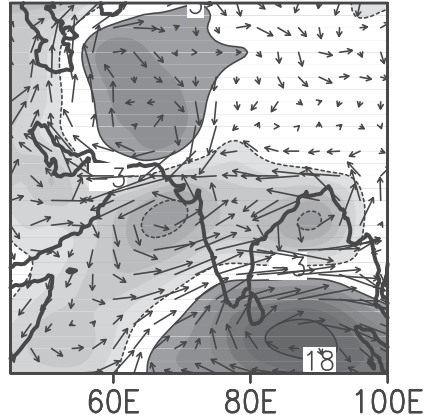

(i) DAY (5)

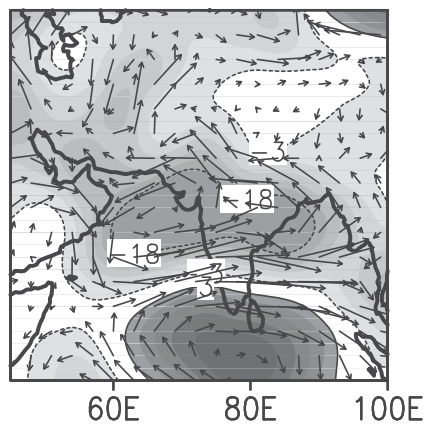

18

15

12

9

6 3 $-3$

$-6$

$-9$

$-12$

$-15$
FIG. 3. Sequence of composited midtropospheric $(650-500 \mathrm{hPa})$ circulation anomalies, winds (arrows; $\mathrm{m} \mathrm{s}^{-1}$ ), and streamfunction (shading; $\times 10^{-5} \mathrm{~s}^{-1}$ ) showing evolution of MTCs starting from day -3 until day 7 with 1-day interval.
Arabian Sea imply the formation of MTC around Gujarat. Subsequently, the cyclonic circulation deepens and is accompanied by gradual strengthening of the west Asian anticyclone giving rise to a north-south-oriented quasi-stationary anticyclone-cyclone circulation pair
(Figs. 3d-f). The anticyclonic anomaly over west Asia is typically associated with midlevel subsidence over the monsoon heat-low region during the summer monsoon period, which has been argued to be induced by enhanced convective activity over the $\mathrm{BoB}$ and northeastern India 
(a) DAY (-3)

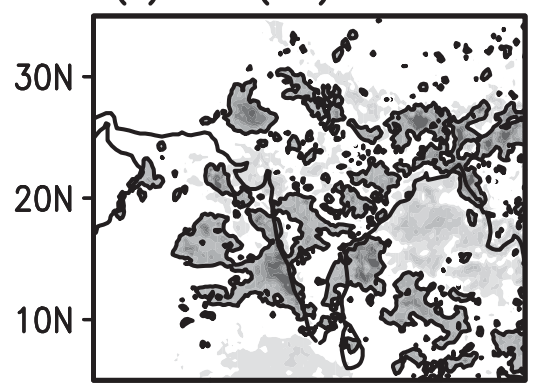

(d) DAY (0)

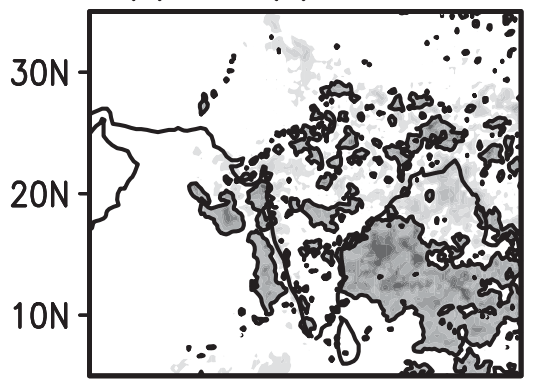

(g) DAY (3)

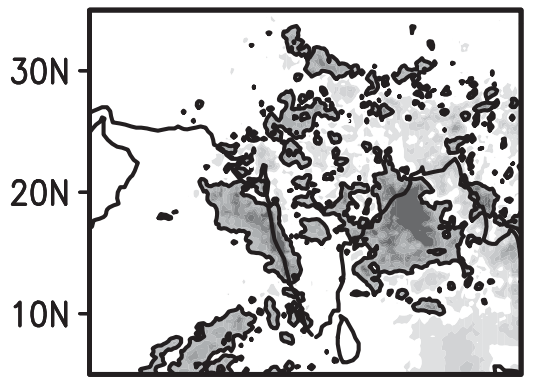

(j) DAY (6)

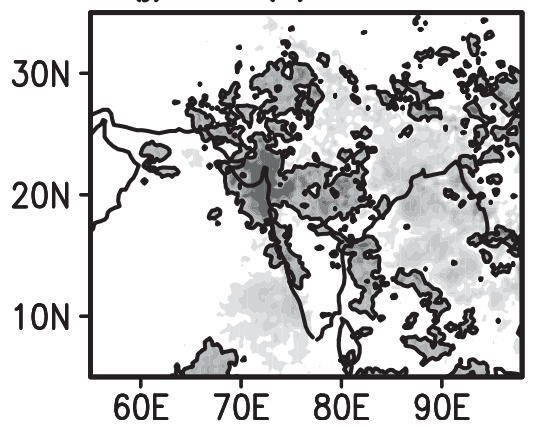

(b) DAY (-2)

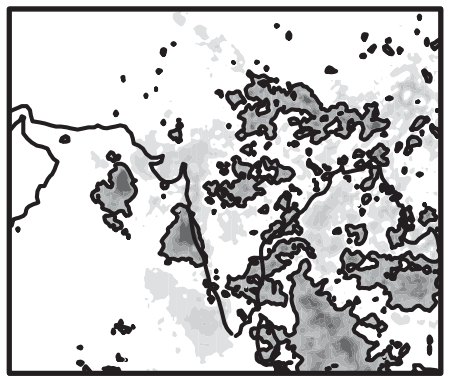

(e) DAY (1)

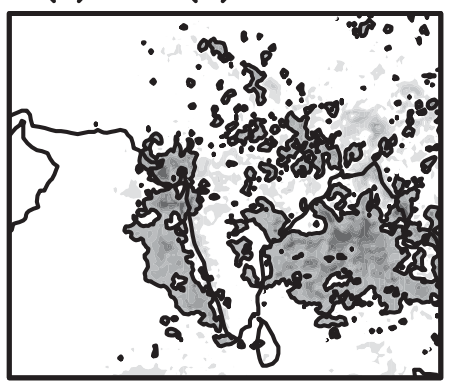

(h) DAY (4)

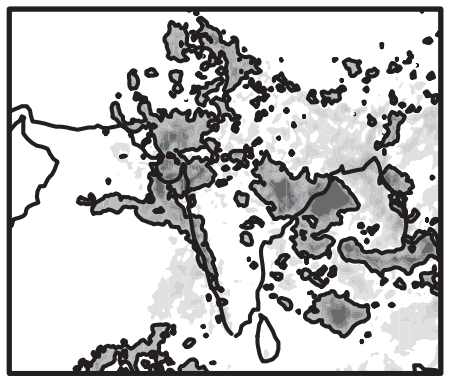

(k) DAY (7)

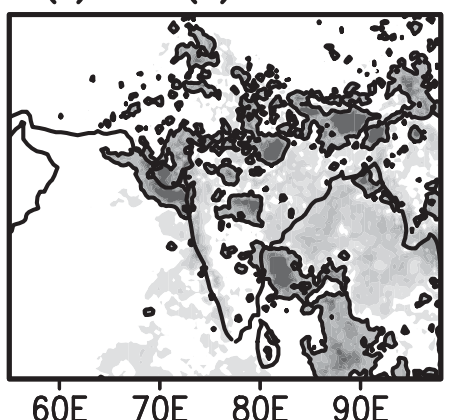

(c) $\operatorname{DAY}(-1)$

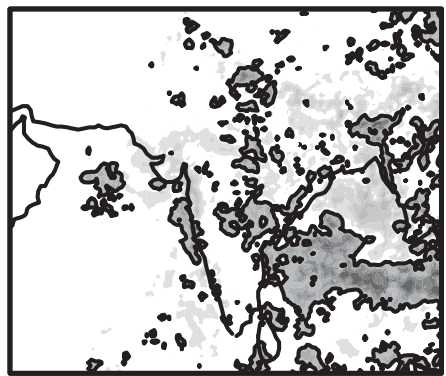

(f) DAY (2)

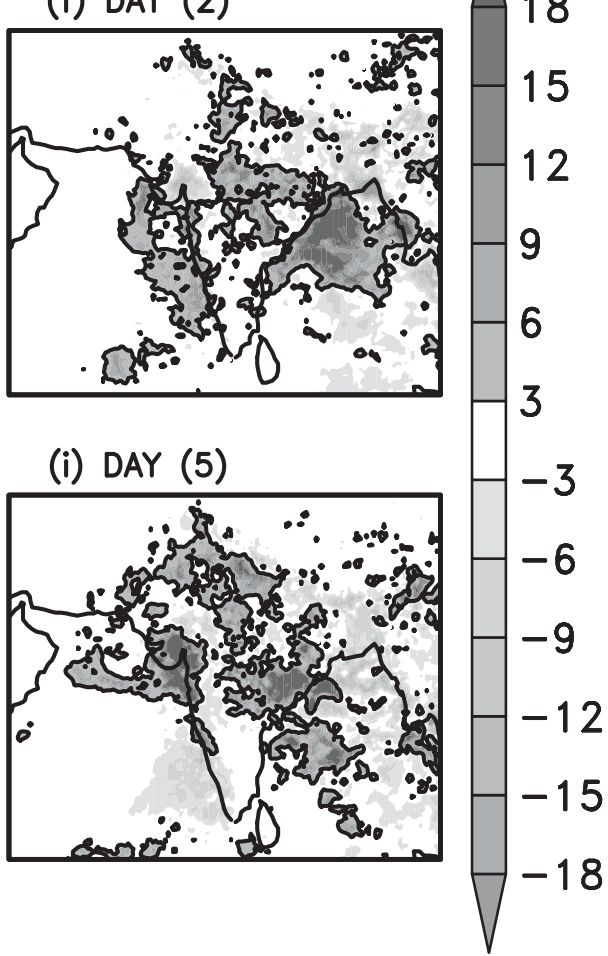

FIG. 4. As in Fig. 3, but for rainfall $\left(\mathrm{mm} \mathrm{day}^{-1}\right)$.
(Das and Bedi 1981; Bollasina and Nigam 2011), involving a Rossby wave dynamical response (Tyrlis et al. 2013). Two distinct anomalous cyclonic circulation centers, located over the northern Arabian Sea and $\mathrm{BoB}$, become more noticeable by day 2 and later tend to organize along the east-west-oriented cyclonic gyre by day 5 .
The daily evolution of rainfall anomalies shows significant variations over the central Arabian Sea and southern BoB prior to MTC development (days $-3,-2,-1$; Figs. $4 a-c)$. Enhancements in precipitation anomalies are noted across the Western Ghats coinciding with the development of MTC circulation on day 0 . It is interesting to note that the organized 
precipitation structures over the $\mathrm{BoB}$ tend to move northward during days 0-3 (Figs. 4d-g). The northwestsoutheast-oriented precipitation structures across peninsular India tend to organize and acquire a more west-east orientation. One can also notice a systematic increase of organized rainfall over the western parts of India (Figs. 4h-k) and more intense precipitation centered over Gujarat, in particular, during the mature stages of MTC (day 4 and later). In addition, an analysis of time evolution of the rainband over BoB demonstrates northward migration of the monsoon organized convection signal from the equatorial Indian Ocean to the central BoB (Fig. 5). Northward migration of rainband anomalies, with relatively weaker magnitudes as compared to the BoB, is observed over the Arabian Sea as well (figure not shown).

The temporal sequence of observed precipitation amounts within three subregions shown in Fig. 6 enunciates the subregional characteristics of precipitation variations during the evolution of MTCs. The boxes in Fig. 6a show the different subregions over which the precipitation is averaged: western India centered over Gujarat (box b), east coast of India near BoB (box c), and central part of Western Ghats (box d). Notice that the subregions centered at Gujarat and BoB show an overall increasing tendency of rainfall from day -5 through day +5 (Figs. $6 \mathrm{~b}, \mathrm{c}$ ). The evolution of vertical variation of specific humidity over western India shows a steady buildup at midtropospheric levels favoring heavy rains during the later stages of the MTC (Fig. 7). However, the temporal evolution of precipitation within the box centered at the Western Ghats shows a strikingly different pattern by displaying a sharp increase in precipitation prior to MTC evolution (Fig. 6d), which is followed by a slight decline and subsequent rise once MTC is established. The IMD gauge data differ substantially from the satellite-based TRMM 3B42 estimates. The mean summer monsoon precipitation over the Western Ghats is known to have significant contributions from shallow orographic rainfall (e.g., Konwar et al. 2014; Shige et al. 2017), although deep clouds associated with stratiform precipitation tend to prevail over this region during active phases of the monsoon (e.g., Chattopadhyay et al. 2009; Virts and Houze 2016; Pokhrel and Sikka 2013). What is the role of the enhanced rainfall activity over the Western Ghats and adjoining Arabian Sea as well as the BoB organized convection (Figs. $4 a-c$ and $6 c, d)$ to the formation of this special class of disturbances over the northern Arabian Sea?

\section{d. Latent heating structure associated with MCS}

To address this question, we present here snapshots of vertical heating profiles from the gridded orbital $3 \mathrm{G} 31$

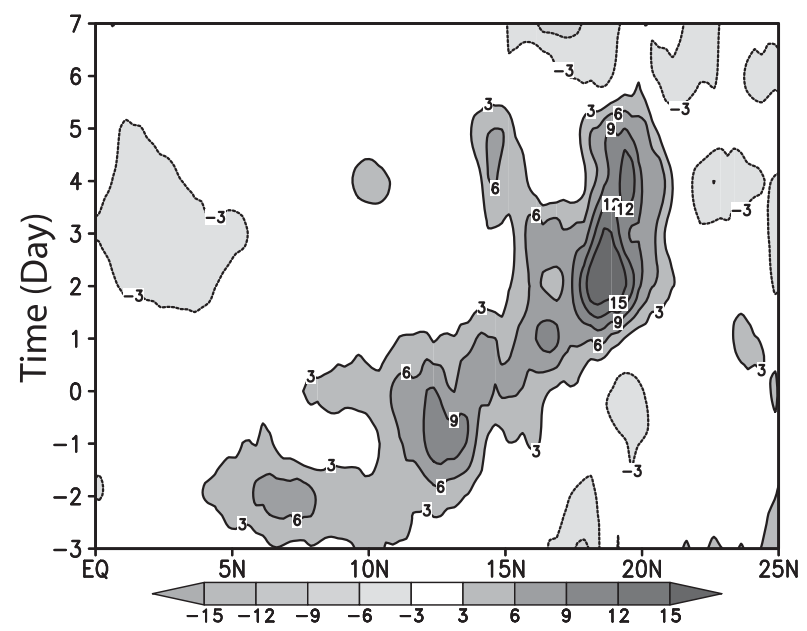

FIG. 5. Hovmöller plot of rainfall anomaly composites $\left(\mathrm{mm} \mathrm{day}^{-1}\right)$ averaged over the BoB during evolution of MTC.

$\mathrm{CSH}$ dataset over the Arabian Sea and adjoining land areas of the Western Ghats. The profiles are selected for all the cases that coincide with TRMM satellite passes over this region prior to onset of MTC (i.e., days $-3,-2,-1)$, when there is significant precipitation. We used the satellite-swath data and constructed the profiles by averaging only the raining grids during the time of the satellite cross. Figure 8 shows examples of $\mathrm{CSH}$ heating profiles averaged over raining grids in the satellite swaths. It is interesting to notice that stronger latent heating occurs predominantly above $600 \mathrm{hPa}$, with the maximum at about $400 \mathrm{hPa}(6.5$ or $7 \mathrm{~km} \mathrm{MSL})$. Maximum heating rates typically lie in the range $0.8-2.5 \mathrm{~K} \mathrm{~h}^{-1}$ in all these cases. A few profiles indicate significant cooling $\left(0.3-0.8 \mathrm{~K} \mathrm{~h}^{-1}\right)$ at lower levels. The mean climatological heating profile over the Arabian Sea and adjoining land region $\left(10^{\circ}-21^{\circ} \mathrm{N}, 62^{\circ}-74^{\circ} \mathrm{E}\right)$ for the entire summer monsoon [June-September (JJAS)] period (dotted curve) shows heating between 800 and $300 \mathrm{hPa}$ in the range of $0.1-0.16 \mathrm{~K} \mathrm{~h}^{-1}$. While the climatological mean profile does not exhibit clear heating maxima, a significant amplification of the latent heating of the MCS can be noted in Fig. 8. This kind of top-heavy heating structure, with cooling below, clearly indicates the presence of abundant stratiform precipitation associated with MCS activity (e.g., Schumacher and Houze 2003; Kodama et al. 2009; Choudhury and Krishnan 2011). It is also important to mention here that the mean heating over the region of heavy rainfall over the Western Ghats is known to be associated with shallow clouds (Romatschke and Houze 2011; Konwar et al. 2014; Kumar et al. 2014; Shige and Kummerow 2016; Shige et al. 2017; Utsav et al. 2017). Nevertheless, studies have also shown that deep clouds associated 

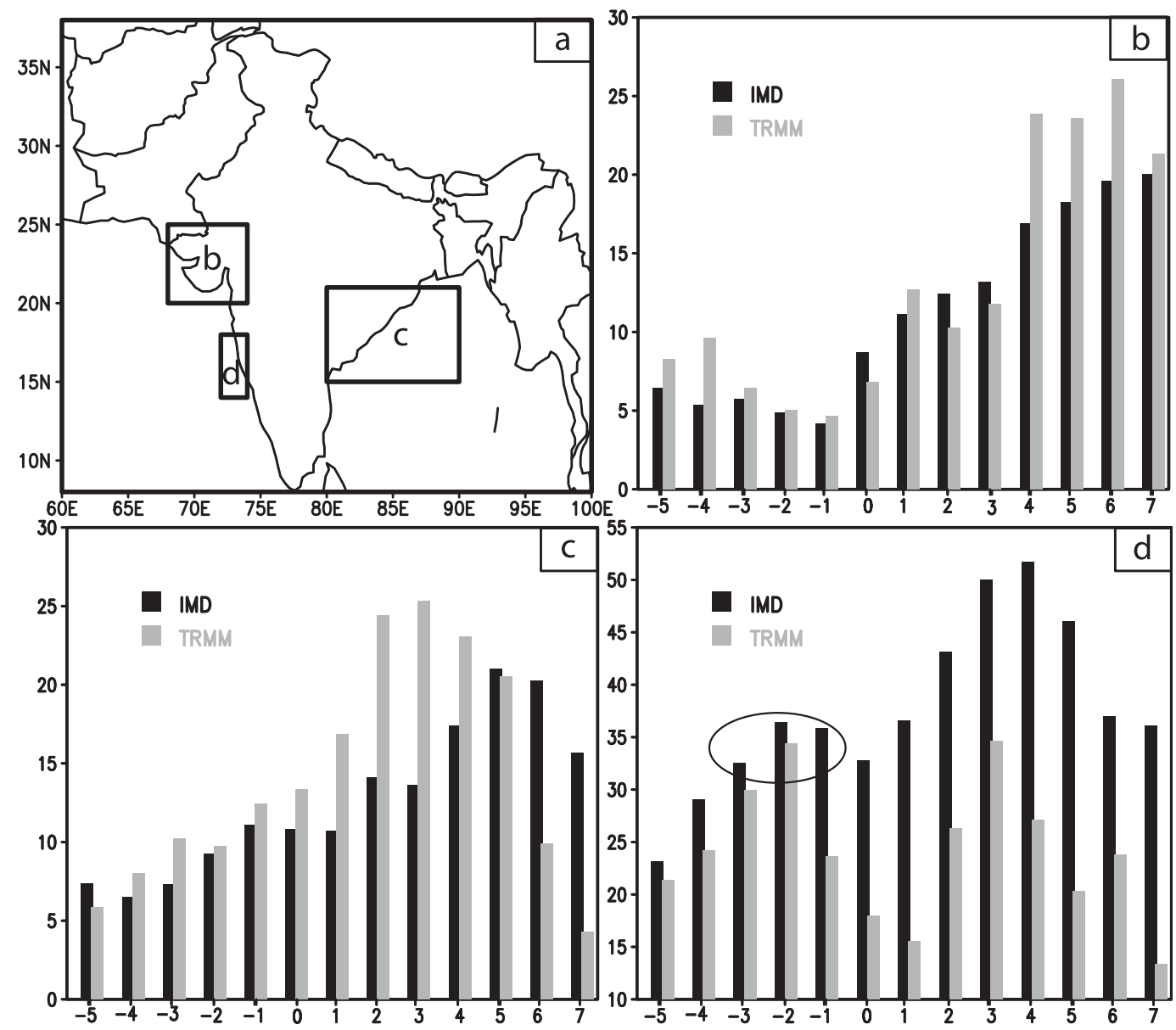

FIG. 6. (a) Map of India showing different subregions (boxes) over which rainfall is averaged. Composited time evolution of area-averaged rainfall $\left(\mathrm{mm} \mathrm{day}^{-1}\right)$ before and after the onset of MTC over (b) western India, (c) BoB and adjoining land region, and (d) Western Ghats. The circle in (d) denotes the increase in precipitation over the region prior to the onset of the MTC.

with stratiform precipitating systems and large MCSs are prevalent on subseasonal scales over the Arabian Sea and adjoining Western Ghats (WGs), especially during active phases of the Indian summer monsoon (e.g., Chattopadhyay et al. 2009; Virts and Houze 2016; Pokhrel and Sikka 2013). The TRMM PR data of convective and stratiform fractions for the aforementioned MTC examples also reveal that on days prior to the onset of MTC, nearly $50 \%-60 \%$ of rain fractions originate from stratiform precipitating MCSs (figure not shown).

Studies have pointed out that large populations of stratiform-type precipitation, characterized by maximum heating amplitude around $400 \mathrm{hPa}$, is crucial for intensification of midlevel cyclonic circulation in the tropics and monsoon regions (Schumacher and Houze 2003; Kodama et al. 2009; Choudhury and Krishnan 2011) and also conducive for northward propagation of organized convection during the Indian summer monsoon (Chattopadhyay et al. 2009; Kumar and Krishnamurti 2016). Since the source term for potential vorticity is the vertical gradient of heating, the heating profiles of Fig. 8 suggest that the formation of MTCs over the northeastern Arabian Sea is likely shaped by the profile of heating from organized MCS over the Arabian Sea and perhaps also in the Western Ghats region if we accept the CSH scheme's assumption that "stratiform" precipitation identified there has a similar vertical profile to other regions. In section 3, we shall present results from GCM sensitivity experiments, which allow us to test the above hypothesis.

\section{e. Monsoon intraseasonal variability and MTC genesis}

It was earlier noted that rainfall and circulation anomalies over the BoB and peninsular India exhibited 


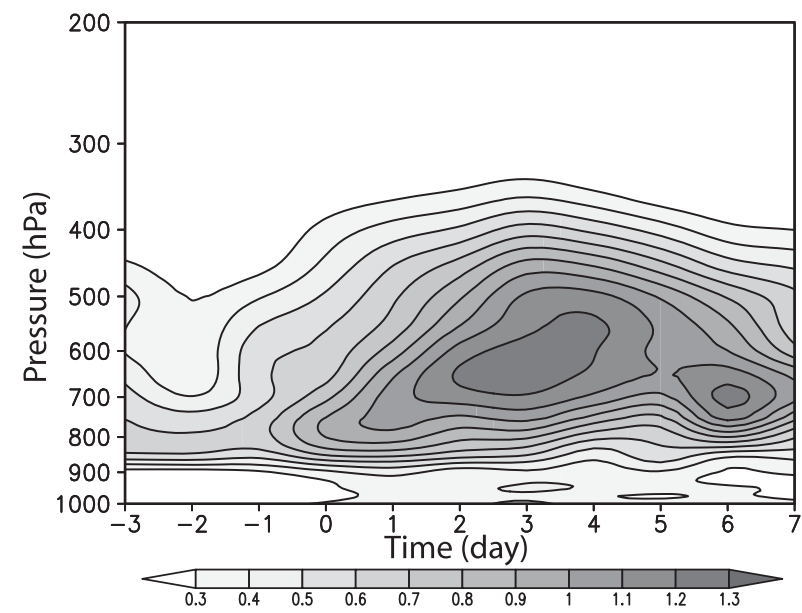

FIG. 7. Pressure-time section of specific humidity $\left(\mathrm{kg} \mathrm{kg}^{-1}\right)$ averaged over western India and the adjoining sea region.

a northward movement prior to commencement of the MTC (Figs. 3-5). This suggests that at least some developments of MTC over the northern Arabian Sea are linked with the northward propagation of the subcontinent-scale band of convection associated with monsoon intraseasonal variations. Satellite measurements of OLR serve as a useful proxy for inferring intraseasonal variations in organized deep convection over the tropics and the Indian summer region (e.g., Lau and Chan 1986; Krishnan et al. 2000; Krishnamurthy and Shukla 2008). In fact, the evolution of OLR anomalies over India during the active and break periods is known to exhibit good correspondence with the lag composites of IMD rainfall anomalies (Krishnamurthy and Shukla 2007).

Figure 9 shows the composite map of OLR anomalies averaged over the three days prior to commencement of the MTC. Enhanced large-scale organized convective activity prevails over much of the Indian subcontinent, particular over the Arabian Sea, peninsular India, and the southern BoB prior to the commencement of MTC over the northern Arabian Sea, as evidenced from the dominance of negative OLR anomalies. The large-scale organization of convection is also suggestive of stronger mean monsoon circulation (e.g., Sikka and Gadgil 1980; Choudhury and Krishnan 2011). The negative OLR anomalies are flanked by positive OLR anomalies over subtropical west Asia, including areas in north Pakistan, Afghanistan, and the adjoining Middle East. The positive OLR anomalies over subtropical west Asia are associated with a thermally generated surface low pressure zone (a heat low-typically capped by high pressure in midlevels because of enhanced thickness) that extends

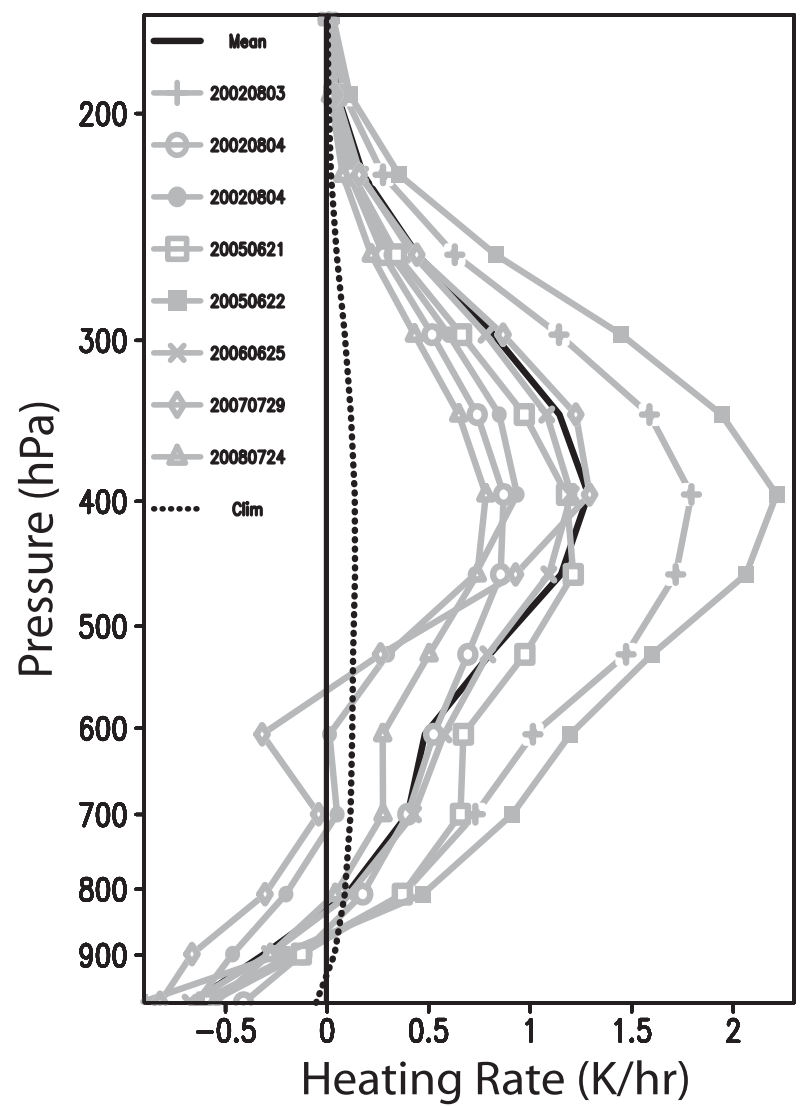

FIG. 8. Examples of vertical heating profile $\left(\mathrm{Kh}^{-1}\right)$ from the 3G31 V7 CSH dataset during days prior to the MTC onset (days $-3,-2,-1)$ for cases where a satellite swath was available over the Arabian Sea and Western Ghats. The black solid curve shows the mean of all the eight different heating profiles. The dotted curve shows the JJAS climatological heating for the region over which the satellite swaths were sampled $\left(10^{\circ}-21^{\circ} \mathrm{N}, 62^{\circ}-74^{\circ} \mathrm{E}\right)$.

westward toward the Mediterranean Sea (Bitan and Saaroni 1992; Saaroni et al. 2010; Tyrlis et al. 2013), related geostrophically to the anomalous midtropospheric anticyclone (Fig. 3).

To bring out the role of subseasonal convective signal during evolution of MTCs, we subjected the daily OLR anomalies to a 10-90-day bandpass filter (Duchon 1979). The low-pass filter screens out high-frequency variations and retains only the low-frequency subseasonal signal. Figure 10 shows the space-time evolution of the lowpass-filtered OLR anomalies with respect to the onset day of MTCs (day 0) over western India. It can be seen that convective anomalies extend across the equatorial Indian Ocean with a strong signal over the eastern side on day -12 . Concurrent suppression of convection is also noted over the central and northern regions of the Indian subcontinent extending into Saudi Arabia across the Arabian Sea. During the subsequent days, a gradual 


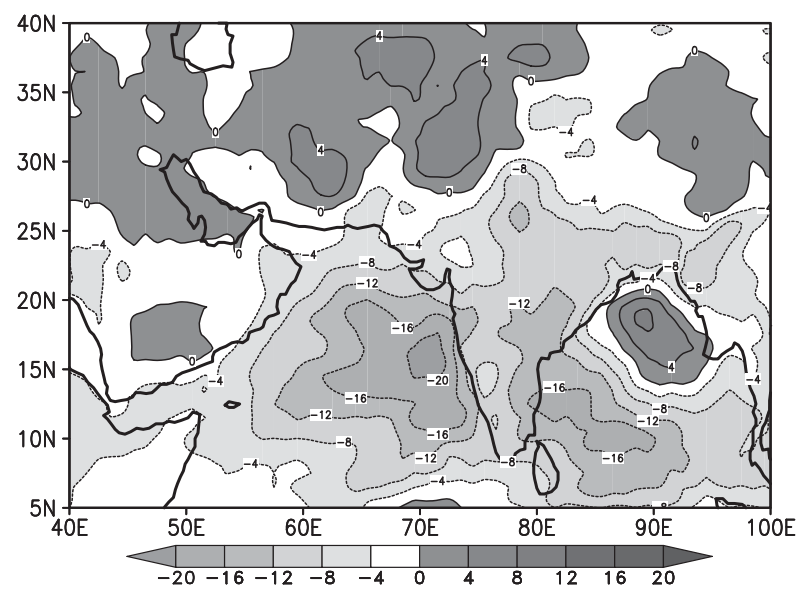

FIG. 9. Composite map of OLR anomalies $\left(\mathrm{W} \mathrm{m}^{-2}\right)$ for days prior to onset of MTC (days $-3,-2,-1$ ).

northward movement of an organized convective envelope into the Indian landmass can be noted. While convective activity enhances over the east-central Arabian Sea and Western Ghats during day -3 , we also notice development of dipole-type convective centers over the northeast Arabian Sea and southwest BoB. The positive OLR anomalies over subtropical west Asia indicate clear-sky conditions and suppressed convection over the region. Further, these positive OLR anomalies over subtropical west Asia are coincident with strong midlevel subsidence (figure not shown), consistent with the tropical dominant balance of vertical advection and diabatic terms in the thermodynamic equation. The convective maximum over the Arabian Sea further intensifies and slowly progresses northward from day 0 to day +3 over the western part of India. Figure 11 shows the latitude-time section (Hovmöller plot) of the 10-90-day-filtered convective signals from day -12 to day +5 obtained by averaging the anomalies over the longitude band between $60^{\circ}$ and $100^{\circ} \mathrm{E}$. It is important to note that the time axis is with reference to the date of the MTC onset, that is, day 0 . One can note a clear northward propagation of organized convection from the equator to $20^{\circ} \mathrm{N}$ with an approximate latitudinal propagation speed of $1^{\circ} \mathrm{day}^{-1}$.

Enhancement of organized convection over peninsular India and the BoB can induce stronger descent over the Iran-Turkmenistan-Afghanistan region through a thermally direct circulation (Bollasina and Nigam 2011; Das and Bedi 1981). Furthermore, subsidence over subtropical anticyclones is often associated with intense radiative cooling (Rodwell and Hoskins 1996; Wu et al. 2009). Keeping this in view, we examined variations in atmospheric radiation over the west Asian region using the tropospheric temperature tendency profiles due to radiation from MERRA-2. This includes both solar and terrestrial radiative heating. Our analysis of anomaly composites of midtropospheric $(500-450 \mathrm{hPa})$ radiative heating (Fig. 12) reveals enhanced cooling at midtropospheric levels over the west Asian region during days $-2,-1,0$, and +1 of the MTC evolution (negative heating values: shaded light gray region in Fig. 12), indicating an enhanced loss of radiation to space. In particular, the midtropospheric cooling is prominently noticed over the desert and mountainous regions of Iran-Turkmenistan-Afghanistan 2 days prior to day 0 (Fig. 12a). With the formation of the MTC, the radiative cooling anomaly spreads over a larger area of subtropical southwest Asia, attains peak intensity 2 days later, and gradually subsides thereafter (Figs. 12b,c).

In summarizing the foregoing analysis, it is noted that midtropospheric cyclogenesis over the northern Arabian Sea occurs in a background environment comprising large-scale organized monsoon convection embedded with prevailing stratiform precipitating systems over the Western Ghats and adjoining Arabian Sea as well as over the BoB and large-scale subsidence over subtropical west Asia. It is seen that the creation of this background environment is facilitated by slow northward propagation of the intraseasonal rainband.

\section{Phenomenological model synthesis for MTC genesis}

This section focuses on model simulation experiments designed to provide a phenomenological basis for comprehending the effects of enhanced latent heating from the MCS and radiative cooling over west Asia on the genesis of MTCs over the northern Arabian Sea. The model used here is a dry atmospheric GCM forced with prescribed heating balanced by damping terms (Rayleigh friction and Newtonian cooling) in the momentum and thermodynamic equations (Choudhury and Krishnan 2011). The simulation experiments considered in this study are essentially steady-state solutions of a resting atmosphere's response to fixed forcing (heating) and dissipation. All simulations commence from a quiescent background atmospheric state, and the model is integrated for 100 days to obtain a steady-state or near-equilibrium response. Similar simplified modeling experiments have been undertaken in the past to address various aspects of monsoon circulation dynamics (e.g., Hoskins and Rodwell 1995; Krishnan and Kasture 1996; Schumacher et al. 2004).

\section{a. Design of control experiment}

The CTRL experiment utilizes three-dimensional JJAS climatological latent heating profiles that are 
(a) DAY $(-12)$

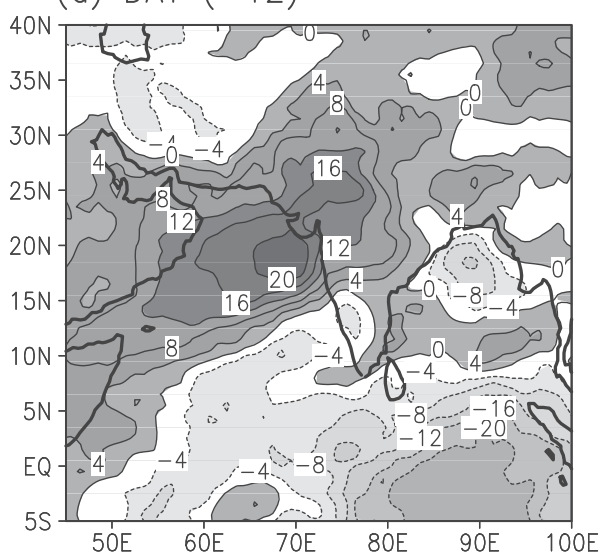

(b) DAY (-9)

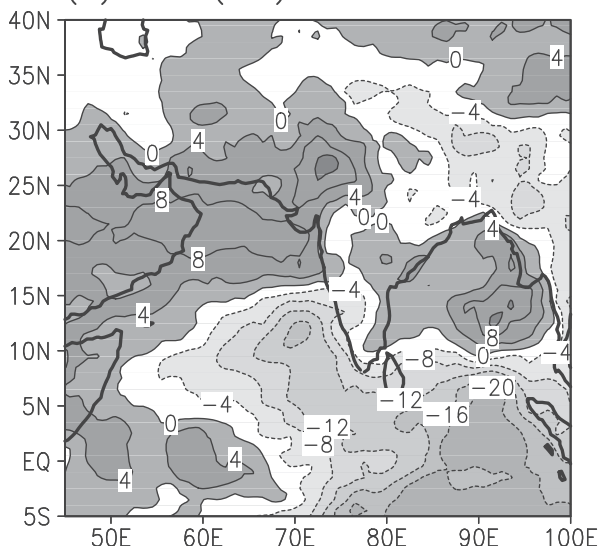

(c) DAY (-6)

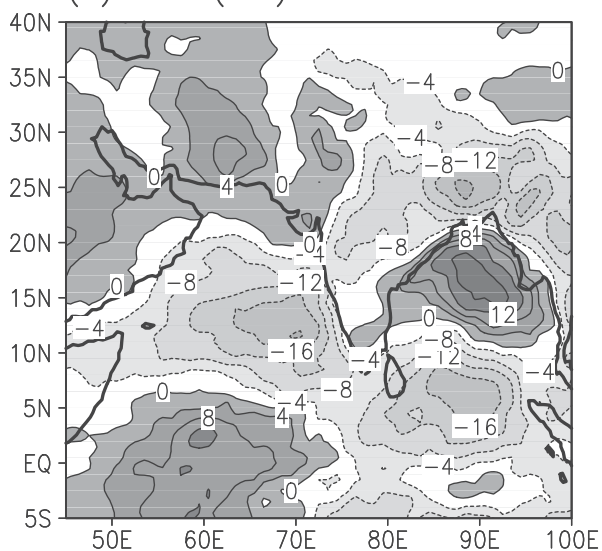

(d) DAY (-3)

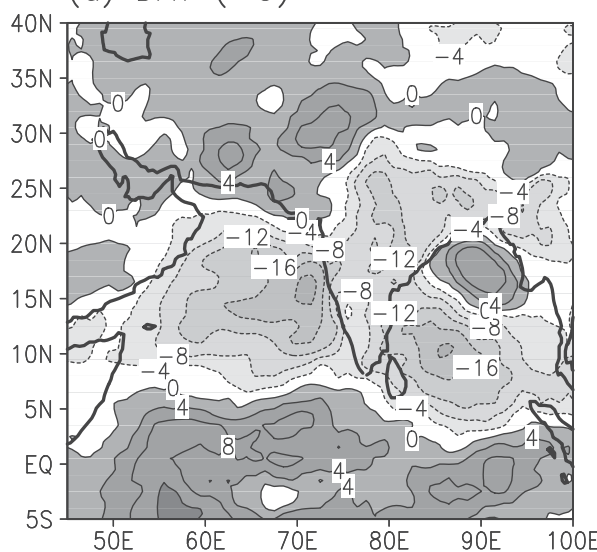

(e) DAY (0)

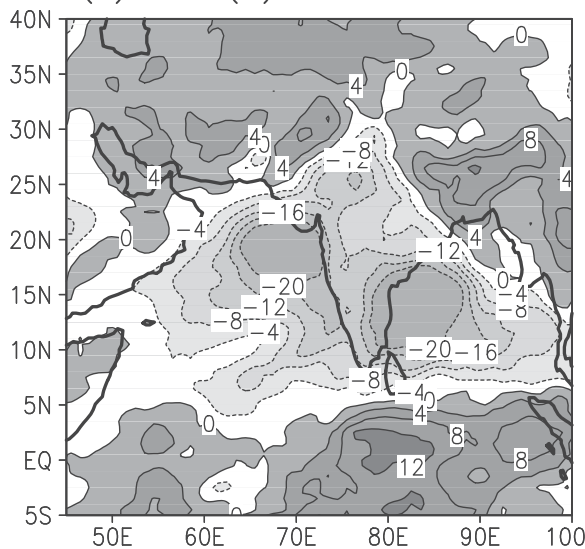

(f) $\operatorname{DAY}(3)$
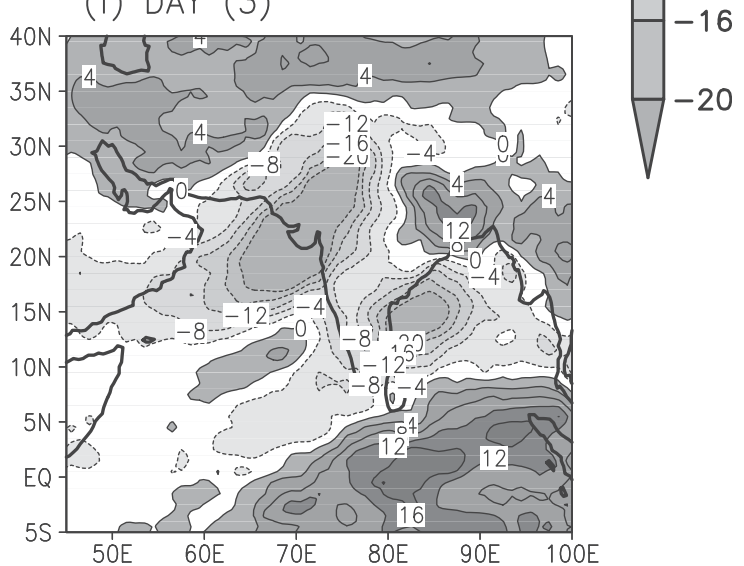

20

16

12

4

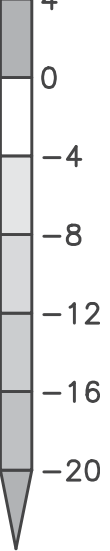

FIG. 10. Space-time evolution of 10-90-day-filtered OLR anomalies over the monsoon region with respect to the onset date of MTC (day 0): (a) day -12 , (b) day -9 , (c) day -6 , (d) day -3 , (e) day 0 , and (f) day 3.

constructed using TRMM PR 3A25 JJAS monthly data. The total heating profile over any grid point is determined by TRMM PR surface rainfall observations and stratiform as well as the convective heating profiles. The deep convective heating is positive for the entire troposphere, while the stratiform heating profile has an elevated condensational heating maximum and evaporative cooling below the freezing level. First, the observed (TRMM PR 3A25) rainfall at any grid point is partitioned into convective and stratiform components, depending on the observed rain fraction at that grid point. The three-dimensional (3D) latent heating at 


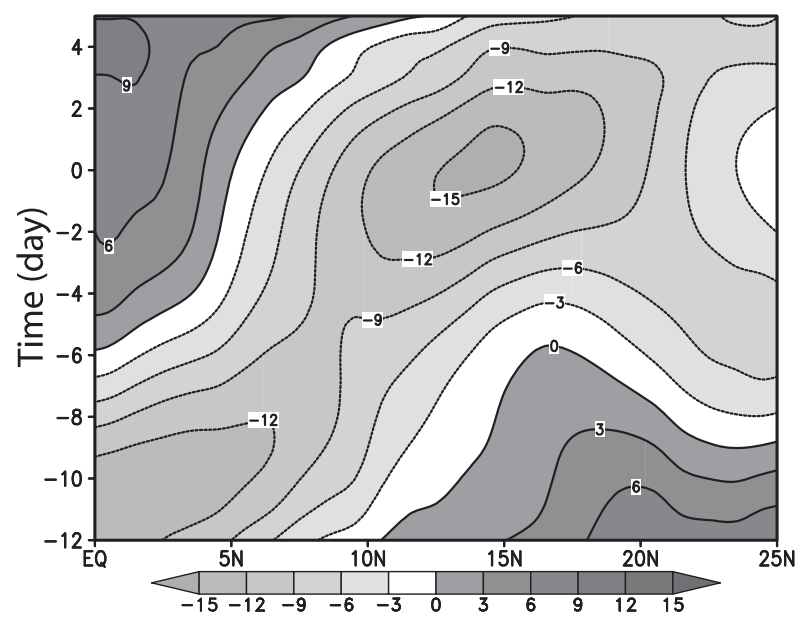

FIG. 11. Hovmöller plot of 10-90-day-filtered OLR anomalies averaged between $60^{\circ}$ and $100^{\circ} \mathrm{E}$ with respect to the onset date of MTC (day 0).

every grid point is then calculated using the surface rain rate, stratiform and convective rain fractions, and a linear combination of the assumed normalized profiles of stratiform and convective precipitation based on Schumacher et al. (2004). For convenience, we refer to the Schumacher et al. (2004)-derived latent heating as SCMLH. The computation of SCMLH is also described in Choudhury and Krishnan (2011). The estimated vertically averaged climatological SCMLH for the boreal summer monsoon (JJAS) is shown in Fig. S1a in the supplemental material. Notice that there are two latent heating maxima located over the Western Ghats and the head of the BoB off the Myanmar coast. Associated with the large-scale organized monsoon convection, the magnitude of latent heating is significant over the $10^{\circ}-$ $25^{\circ} \mathrm{N}$ latitude belt extending from western India to the tropical west Pacific (Choudhury and Krishnan 2011). It is also important to mention that the shallow convective orographic rainfall over the Western Ghats is generally underestimated in the TRMM 3B42 merged product as compared to the IMD rain gauge data (Konwar et al. 2014; Shige et al. 2017). While the SCMLH dataset is known to be a good estimate of latent heating in regions of organized MCS (Schumacher et al. 2007; Ahmed et al. 2016), it has limitations in representing shallow convection over the WG. On the other hand, the TRMM $3 \mathrm{H} 25$ standard product, which is based on spectral latent heating (SLH), provides a realistic representation of shallow convective orographic rainfall over the Western Ghats (e.g., Shige et al. 2004, 2009; see also our Fig. S1c). Since the spatial structure of mean latent heating is crucial for reproducing the mean large-scale circulation response, it is important to construct a realistic 3D mean latent heating field for forcing the atmospheric model. Keeping this in view, we replaced SCMLH only over the domain of the WGs $\left(8^{\circ}-21^{\circ} \mathrm{N}, 70^{\circ}-76^{\circ} \mathrm{E}\right)$ by the SLH product and retained SCMLH at all the other grid points (Fig. S1e in the supplemental material). For convenience, we refer to this merged product as $(\mathrm{SCMLH}+\mathrm{SLH})$.

We performed three experiments to understand the realism of the large-scale mean monsoon response to prescribed mean latent heating from SCMLH, SLH, and the combination (SCMLH $+\mathrm{SLH}$ ), respectively The mean circulation response in the three experiments is shown in the supplemental Figs. S1b, S1d, and $\mathrm{S} 1 \mathrm{e}$, respectively. It can be seen that the mean monsoon midtropospheric circulation response in the SCMLH and (SCMLH + SLH) forcing experiments match well with the ERA-Interim circulation (see supplemental Figs. S1b, 1e, and S2 and Figs. 13a,b). An east-west-oriented cyclonic circulation over the South Asian monsoon region, with the cyclonic maximum over the head of the BoB, can be noted in the mean response (Figs. 13a,b). The monsoon westerly winds can be seen extending from the equator to $15^{\circ} \mathrm{N}$. On the other hand, the midtropospheric monsoon circulation response to the SLH heating is found to be rather different, with the monsoon westerly winds shifted farther northward over the Indian subcontinent (supplemental Fig. S1d). We have also verified that the CTRL experiment based on the (SCMLH + SLH) climatological latent heating captures the dominant monsoon low-level circulation features such as the Indian Ocean cross-equatorial winds, southwesterly flow over the Indian subcontinent, and the monsoon trough over central India (figure not shown). In summary, the climatological mean heating in (SCMLH + SLH) is realistic over the WGs, and also, the large-scale mean monsoon response to this mean heating compares well with the ERA-Interim dataset. Based on these considerations, we have employed the (SCMLH + SLH) climatological heating for all the model sensitivity experiments.

\section{b. Design of sensitivity experiments}

To understand the individual and combined influence of latent heating and subtropical radiative cooling processes on the development of the MTC, three sensitivity experiments are conducted. These experiments differ in terms of the anomalous heating over the following regions: (i) Western Ghats and adjoining Arabian Sea, (ii) $\mathrm{BoB}$, and (iii) subtropical west Asia. The first experiment is designed to investigate the response to latent heating from enhanced MCS activity over the Western Ghats and adjoining sea region prior to establishment of the MTC over Gujarat (see section 2c). The latent 

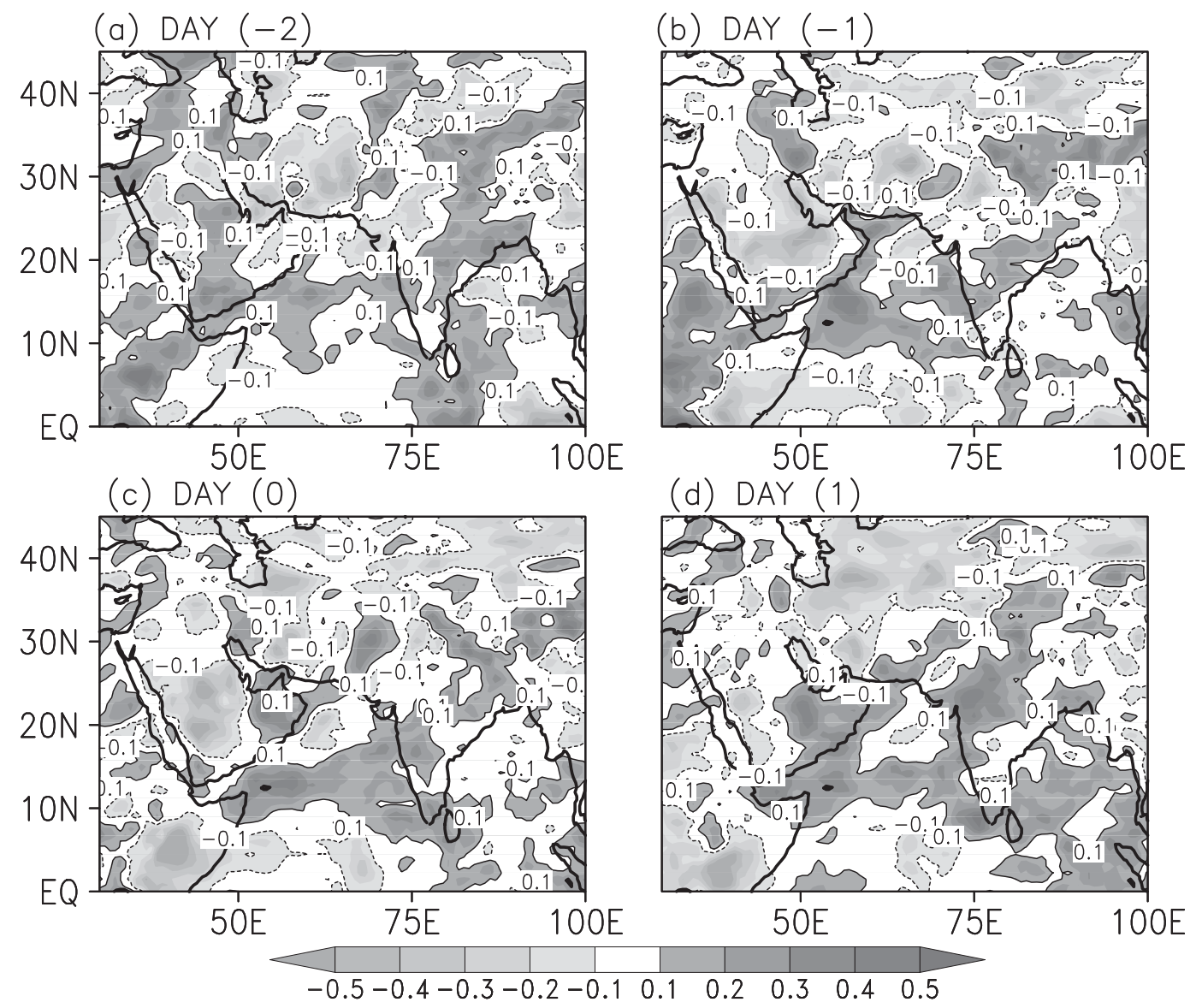

FIG. 12. Composite maps of midtropospheric (500-450 hPa) radiative cooling anomalies $\left(\mathrm{K} \mathrm{day}^{-1}\right)$ from MERRA-2, at different lags, during the evolution of MTC events at (a) day -2 , (b) day -1 , (c) day 0 , and (d) day 1.

heating anomaly is constructed by the following method. First, the observed 3B42 precipitation anomalies are composited for the days $(-3,-2,-1)$ prior to an event. The composited rainfall anomaly is extracted over the Arabian Sea and Western Ghats (AS shown in Fig. 14a) region. Next, we use a fixed, conservative assumption of $40 \%$ stratiform rain fraction and $60 \%$ convective rain fraction at all the grid points, appropriate to temporalmean precipitation across large areas over the Arabian Sea and Western Ghats, as noted by Pokhrel and Sikka (2013). The extracted rain anomalies and the rain fractions are then combined with the assumed normalized heating profiles using the Schumacher et al. (2004) algorithm to obtain the 3D structure of anomalous heating for this experiment. The vertical structure of the anomalous heating profile at a grid point $\left(16^{\circ} \mathrm{N}, 73^{\circ} \mathrm{E}\right)$ is shown in Fig. 14b. This anomalous 3D latent heating is superposed on the JJAS climatological latent heating (SCMLH + SLH) for the first sensitivity experiment, which is referred to as the AS experiment. Figure 14b also shows the vertical structure of heating when the assumed stratiform rain fraction is decreased to $10 \%$ (convective rain fraction increased to $90 \%$ ) and also increased to $75 \%$ (decreased to $25 \%$ ). Intensification of mid- to upper-level heating with a strong positive midlevel heating gradient is observed with the increase in stratiform rain fractions. The right panel of Fig. 14b shows the mean of the eight retrieved vertical profiles of MCS heating over the Arabian Sea and adjoining WGs, which were earlier shown in Fig. 8. The vertical structure of the constructed heating anomaly for higher stratiform rain fractions is similar to the retrieved profile with maximum heating at $400 \mathrm{hPa}$.

In the second sensitivity experiment (ASRC), we examine the combined effects of the anomalous latent heating over the Western Ghats-Arabian Sea and the anomalous radiative cooling over west Asia (Fig. 14c). For this purpose, the radiative cooling diagnosed from MERRA-2 is composited for the days $(-2,-1,0,1)$ during the MTC evolution. Then the composited radiative cooling anomaly for the entire vertical column over the subtropical west Asian region (RC shown in 

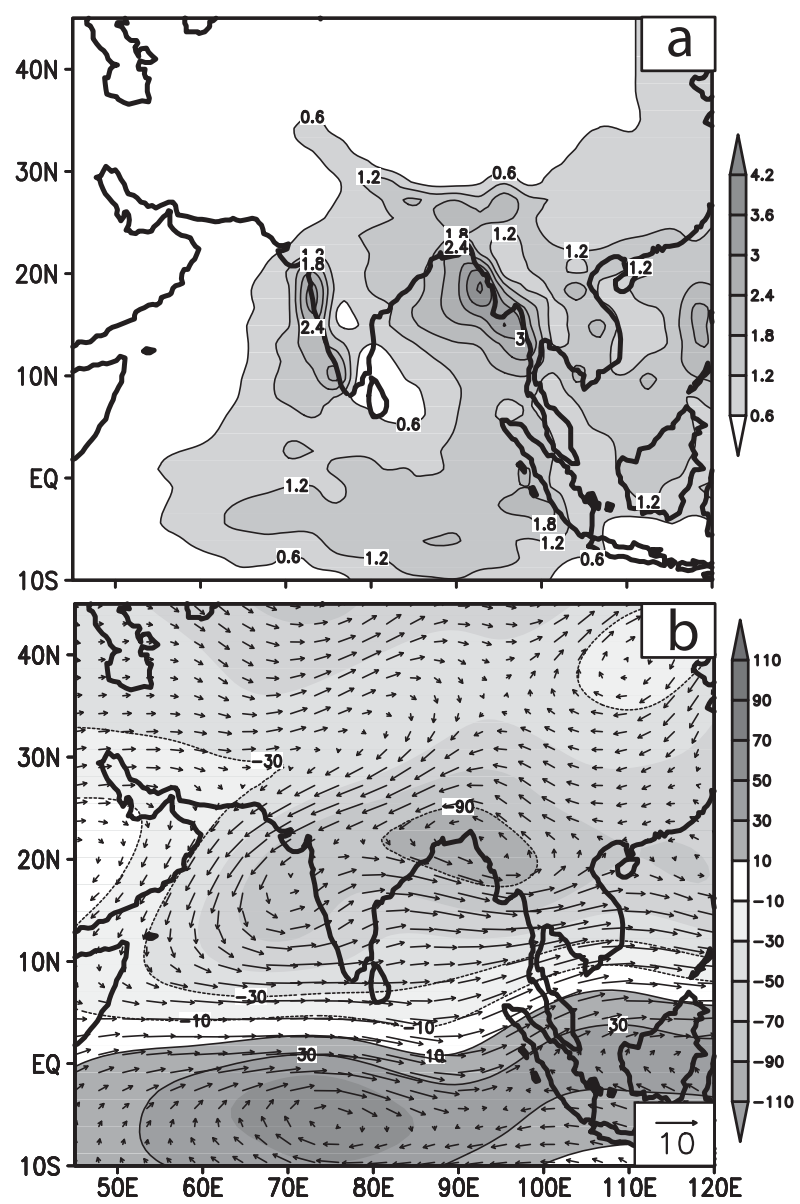

FIG. 13. (a) Vertically averaged climatological JJAS latent heating [(SCMLH + SLH); $\left.\mathrm{Kday}^{-1}\right]$. (b) Midlevel streamfunction (shading; $\times 10^{-5} \mathrm{~m}^{2} \mathrm{~s}^{-1}$ ) and wind (arrows; $\mathrm{m} \mathrm{s}^{-1}$ ) response to climatological latent heating.

Fig. 14c) is extracted and superposed on the CTRL heating along with the AS heating anomaly. We have noticed that the west Asian anomalous radiative cooling shows maximum cooling around the 450-hPa level (figure not shown). The third sensitivity experiment (ASRCBB) incorporates additionally the effect of latent heating anomaly over the southern Bay of Bengal (BB in Fig. 14a). The procedure for calculation of anomalous heating over the BoB is similar to the AS experiment. Steady-state circulation responses are determined for the three experiments (AS, ASRC, ASRCBB) using the forcing described above. The resulting circulation fields are analyzed with respect to the CTRL experiment, as discussed in the following.

\section{c. Response to heating anomalies}

The vertically averaged midlevel total winds and streamfunction from the AS, ASRC, and ASRCBB experiments are shown in Figs. 15a-c. The corresponding circulation anomalies relative to the CTRL experiment are shown in Figs. 15d-f. An intensification of midtropospheric cyclonic circulation over western India and the north Arabian Sea is seen in the AS experiment, along with a slight deepening of the midlevel anticyclone located north of Afghanistan. The simulated circulation anomaly at the surface over the Arabian Sea is rather weak in the AS experiment (figure not shown). In other words, the AS experiment mimics the observed midlevel cyclonic anomaly over the northern part of the west coast of India with weak surface circulation signatures. The ASRC experiment (Fig. 15e) shows that this cooling north of the head of the Arabian Sea contributes an anticyclonic ridge in the area that serves to sharpen the synoptic features seen in the AS experiment, closing off the anomalous cyclone over the Arabian Sea.

With the addition of anomalous heating over the south BoB (ASRCBB), the midlevel cyclonic circulation deepens over the entire monsoon trough region, resulting in an overall strengthening of the background monsoon circulation (Fig. 15c). The anomalous midlevel cyclonic circulation in this case stretches southeastward from Saudi Arabia to the south BoB with an intensified cyclonic streamfunction centered over the northern Arabian Sea (Fig. 15f). The BoB latent heating further leads to strengthening of midlevel subtropical anticyclonic anomalies over west Asia, which can be interpreted as a manifestation of Rossby wave response to monsoon convection (Rodwell and Hoskins 1996; Wu et al. 2009; Tyrlis et al. 2013). Presumably, this shortwavelength (slowly propagating) northwest-southeasttilted Rossby wave signal is importantly shaped by the background flow specific to this region.

We also conducted two additional experiments with $75 \%$ and $10 \%$ stratiform rain fractions over the Western Ghats and adjoining Arabian Sea region to diagnose the contribution of stratiform rain to MTC formation. These experiments are similar to the ASRC except with $75 \%(25 \%)$ and $10 \%(90 \%)$ stratiform (convective) rain fractions for the Arabian Sea heating anomaly (comparison of profiles over a representative grid is shown in Fig. 14b). The midlevel circulation response (Fig. 16) again suggests a northwest-southeast Rossby wave train. As expected from the PV source (vertical gradient of heating), a pronounced intensification of the midlevel Arabian Sea cyclonic vortex occurs in the response to high stratiform rain fractions (Figs. 16a,c). By contrast, cyclonic circulation is more pronounced at lowertropospheric levels for higher convective rain fractions (Figs. 16b,d). Based on the above assessment, the elevated latent heating from the stratiform rain component appears critical for creating the midlevel cyclonic anomaly during MTC events. Additionally, the BoB 

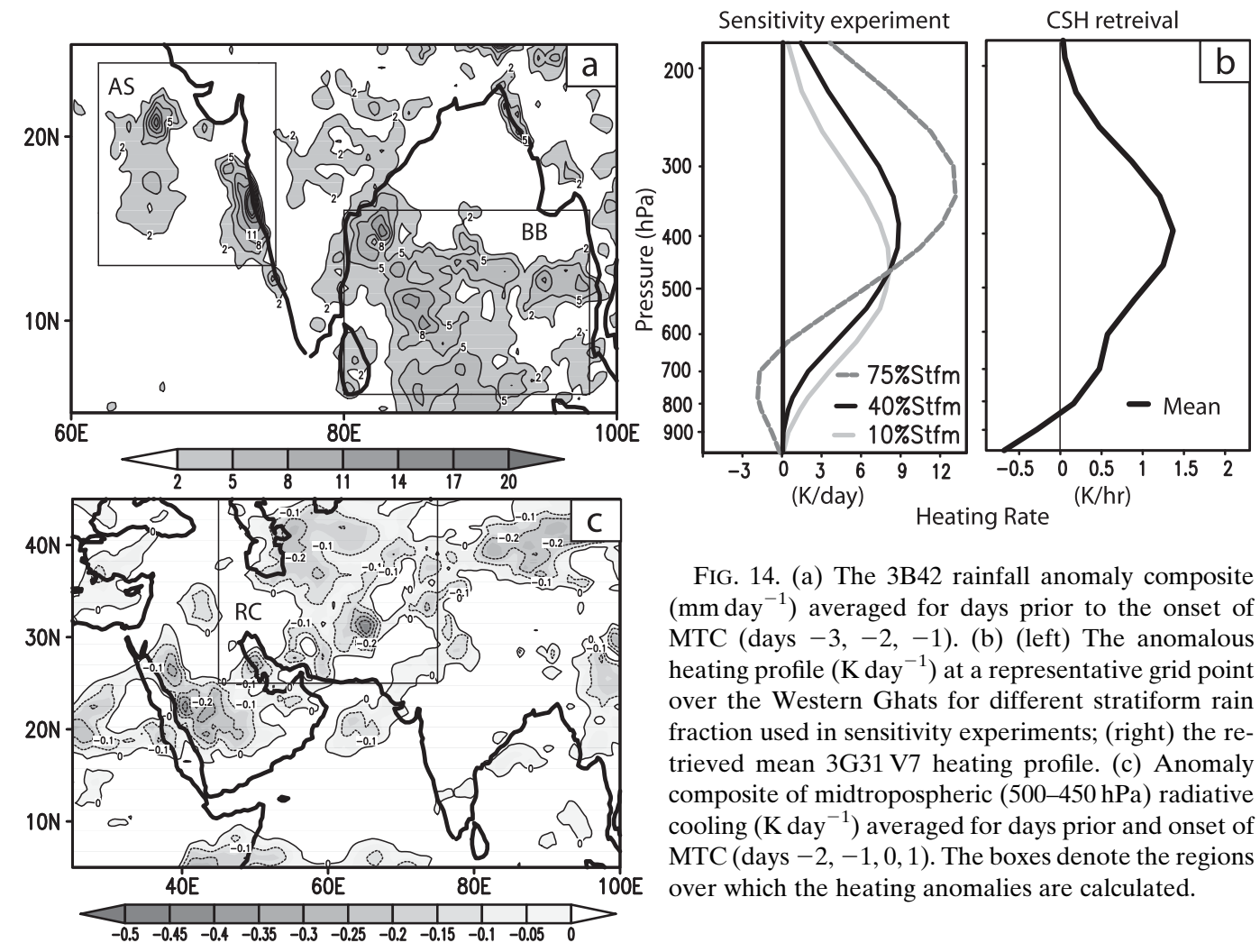

FIG. 14. (a) The 3B42 rainfall anomaly composite $\left(\mathrm{mm} \mathrm{day}^{-1}\right)$ averaged for days prior to the onset of MTC (days $-3,-2,-1$ ). (b) (left) The anomalous heating profile $\left(\mathrm{K} \mathrm{day}^{-1}\right)$ at a representative grid point over the Western Ghats for different stratiform rain fraction used in sensitivity experiments; (right) the retrieved mean 3G31 V7 heating profile. (c) Anomaly composite of midtropospheric $(500-450 \mathrm{hPa})$ radiative cooling $\left(\mathrm{K} \mathrm{day}^{-1}\right)$ averaged for days prior and onset of MTC (days $-2,-1,0,1)$. The boxes denote the regions over which the heating anomalies are calculated.

enhanced convection is crucial for intensification of the Arabian Sea midtropospheric system through its interaction with the strengthened background large-scale monsoon circulation.

The simulated vertical structures of divergence and relative vorticity averaged over the region $15^{\circ}-24^{\circ} \mathrm{N}$, $60^{\circ}-72^{\circ} \mathrm{E}$ (MTC region; see Fig. 15e) is shown in Fig. 17. All three experiments indicate increased convergence (negative divergence) within $850-350-\mathrm{hPa}$ levels with substantial divergence aloft. The CTRL simulation shows lower-level convergence is capped by a divergence above $700 \mathrm{hPa}$. Unlike CTRL, all three experiments show a gradual buildup of enhanced convergence from the surface to $450 \mathrm{hPa}$ (Fig. 17a). The enhanced midlevel convergence is a response to the heating associated with the stratiform rain component of organized MCS together with radiative cooling-driven northerly winds from the west Asian subtropics, which converge into the MTC region. The corresponding strengthening of midtropospheric relative vorticity is evident in all three experiments (Fig. 17b). It is also apparent that maximum intensification of relative vorticity occurs between 650 and $500 \mathrm{hPa}$ (usual levels of MTC occurrence) for all three experiments, consistent with the vertical gradient of heating (Figs. 8, 14).
The vertical structure of geopotential height anomalies averaged between $15^{\circ}$ and $24^{\circ} \mathrm{N}$ for the ASRCBB experiment is shown in Fig. 18a. Negative height anomalies are noticeably centered at the midtropospheric levels between 600 and $400 \mathrm{hPa}$ and located around $60^{\circ} \mathrm{E}$ (Fig. 18a). The associated anomalous vertical velocities display a strong ascent structure at $65^{\circ} \mathrm{E}$, with a weak, shallower secondary center at $75^{\circ} \mathrm{E}$ (Fig. 18b). In contrast with the MTC inferences from the idealized studies of Brode and Mak (1978), where the center of the observed cyclone was located at much lower levels and ascending motions were located to the west of the system, the simulated geopotential anomalies in Fig. 18 are in good agreement with observations. Note that the maximum cyclonic intensity is located around $500 \mathrm{hPa}$, and stronger ascent is located to the east of the system, with peak values centered at about $65^{\circ} \mathrm{E}$ between 400 and $300 \mathrm{hPa}$. These features are in good agreement with the reported observed maximum ascent at $300 \mathrm{hPa}$ by MK68. Furthermore, we have separately validated the results of the AS, ASRC, and ASRCBB sensitivity experiments by using the SCMLH mean climatological heating, and the results are presented in the supplementary figures (Figs. S3-S6). 

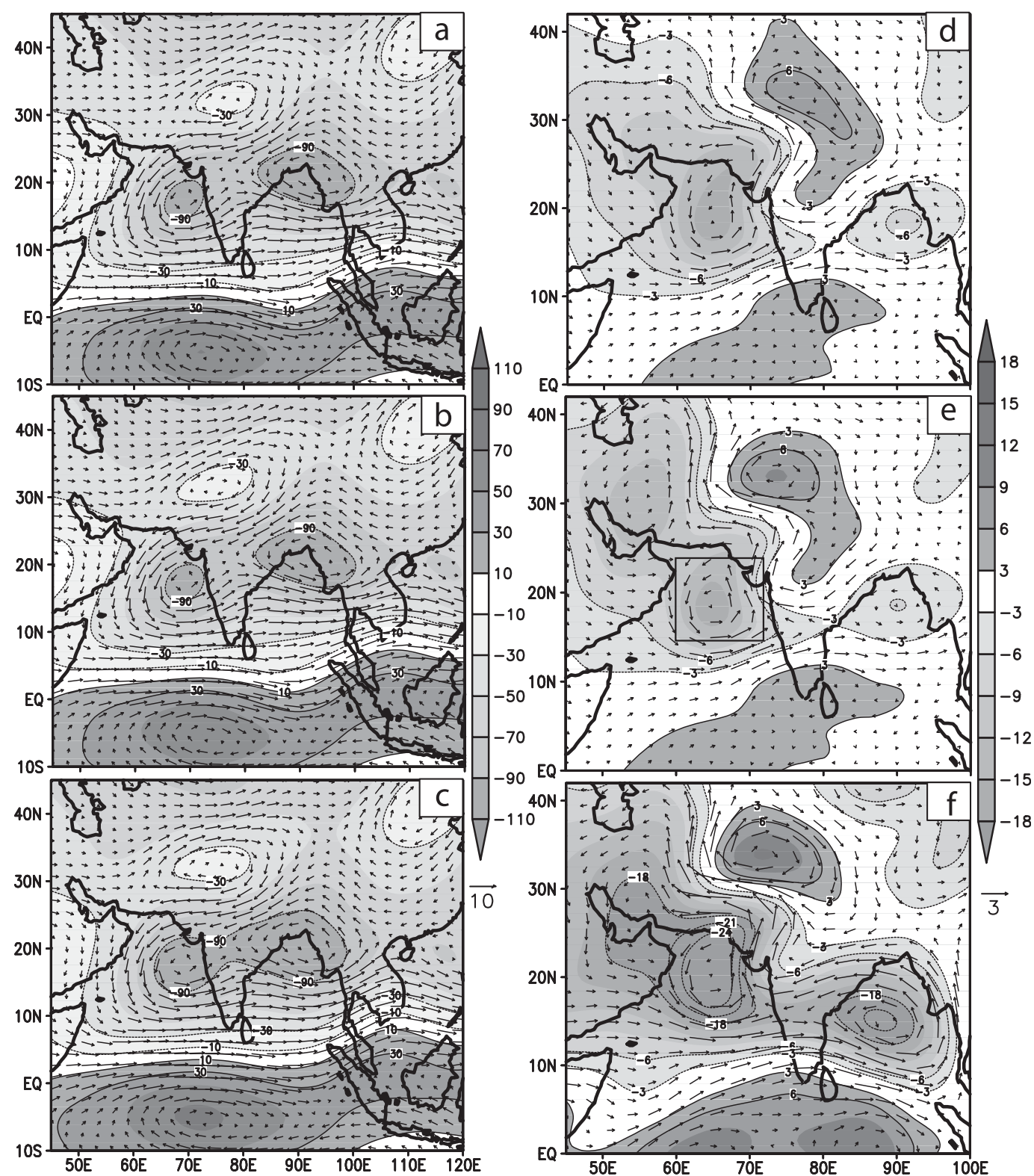

FIG. 15. (left) Model-simulated midlevel total streamfunction (shading; $\times 10^{-5} \mathrm{~m}^{2} \mathrm{~s}^{-1}$ ) and wind (arrows; $\mathrm{m} \mathrm{s}^{-1}$ ) response for three MTC experiments: (a) AS, (b) ASRC, and (c) ASRCBB. (right) Model-simulated midlevel anomalous circulation response shown by winds and streamfunction for different experiments: (d) AS, (e) ASRC, and (f) ASRCBB. The box in (e) denotes the MTC region $\left(15^{\circ}-24^{\circ} \mathrm{N}, 60^{\circ}-72^{\circ} \mathrm{E}\right)$ used for vertical profile computations in Fig. 17.

\section{d. Conceptual sequence of mechanisms}

A conceptual sequence of mechanisms/processes leading to development of MTC is depicted schematically in Fig. 19. Northward propagation of the subcontinent-scale monsoon rainband, associated with the boreal summer ISO, from the equatorial Indian Ocean promotes development of MCSs, giving rise to significant precipitation over the Western Ghats and the adjoining part of the Arabian Sea. Latent heat release from these precipitating systems, particularly from the stratiform rain type with its vertical gradient (PV source, driving for convergence) at midlevels, appears crucial for driving the midtropospheric cyclogenesis over this region.

Concurrently, the northward-propagating rainband over the Indian monsoon region is associated with anomalous subsidence over Afghanistan and adjoining areas of west Asia, leading to enhanced radiative cooling of the lower troposphere, whose vertical gradient 

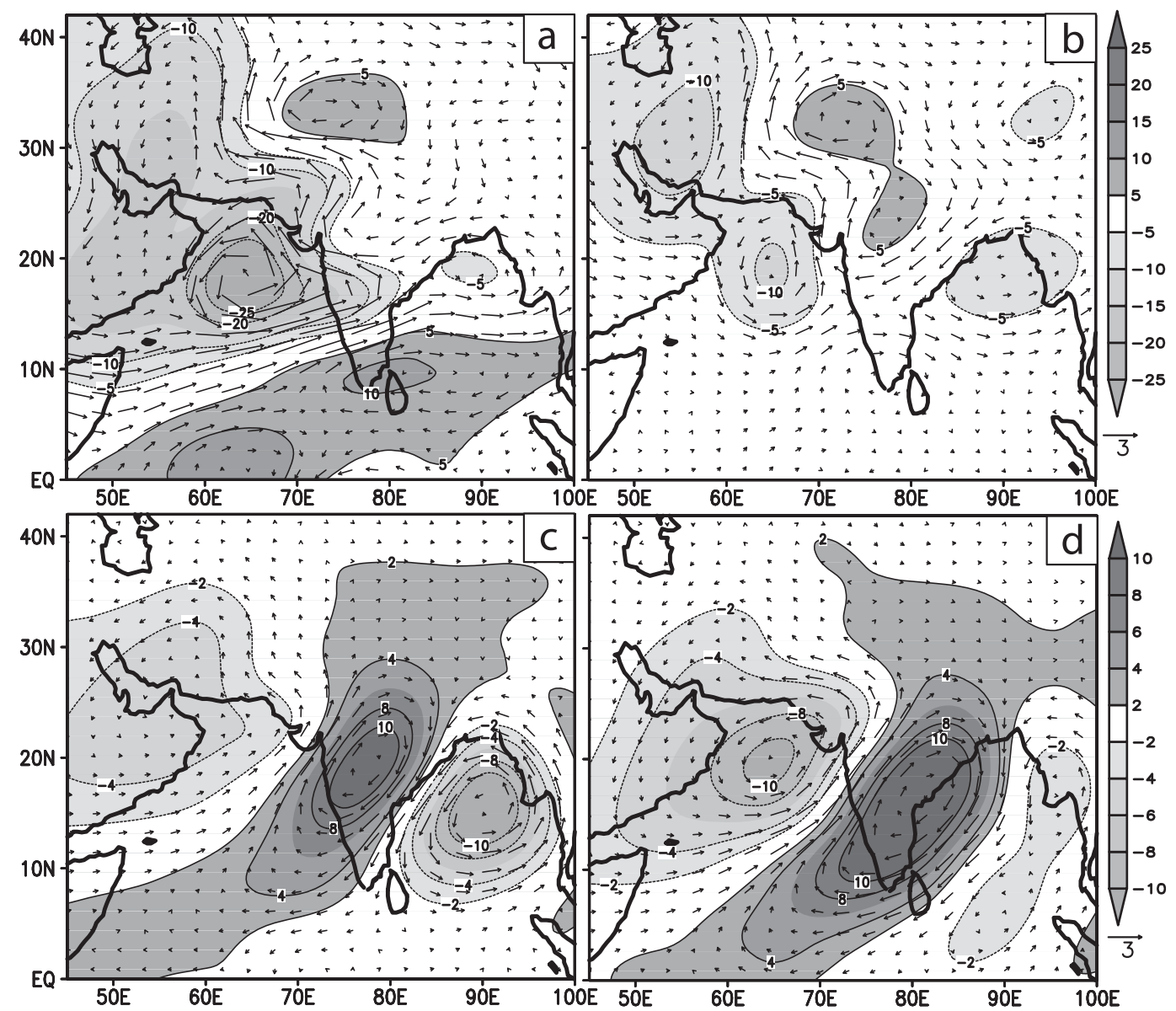

FIG. 16. Model-simulated anomalous circulation response shown by winds (arrows; $\mathrm{m} \mathrm{s}^{-1}$ ) and streamfunction (shading; $\times 10^{-5} \mathrm{~m}^{2} \mathrm{~s}^{-1}$ ) for $75 \%$ and $10 \%$ anomalous stratiform rain. (top) Midlevel response for (a) $75 \%$ and (b) $10 \%$ stratiform; (bottom) low-level response for (c) $75 \%$ and (d) $10 \%$ stratiform.

(PV source, driving for convergence) enhances the anticyclone over the region. This radiative coolingdriven flow directs meridional winds across the north Arabian Sea that help close off and perhaps intensify the midlevel cyclonic vortex over the north Arabian Sea. Further enrichment of midlevel cyclonic vorticity over this region is in tandem supported by organized convection over the $\mathrm{BoB}$ and associated monsoon trough deepening. In summary, the midtropospheric cyclogenesis (within $600-400 \mathrm{hPa}$ ) over the north Arabian Sea is intrinsically promoted by slow northward migration of the broadscale monsoon rainband and shaped locally by changes in latent heatingradiative cooling patterns from three distinct regions (Western Ghats and adjoining sea region, subtropical west Asia, southern BoB).

The onset of MTC over the northeast Arabian Sea and adjoining land regions leads to large amounts of precipitation over the Indian state of Gujarat and the
Western Ghats during the subsequent days (see Figs. 2-4). Much of this rainfall occurs a few days after the inception of the midlevel cyclone (Figs. 3 and 4). A substantial rise in midtropospheric specific humidity occurs 2 days after the MTC onset in accordance with northward migration of the monsoon rain belt from the equatorial Indian Ocean to the central BoB, intensification of the monsoon trough, and the resulting large influx of moisture from the adjacent ocean. Heavy precipitation over Gujarat and the adjoining Western Ghats occurs during the later stage of the MTC, which is often accompanied by westward-propagating disturbances from $\mathrm{BoB}$ that further reinforce the cyclonic circulation and enhances moisture influx into the MTC region. In this sense, the west coast MTCs are part of the overall monsoon, not separate elements, although they are distinct from the midlevel-centered $\mathrm{BoB}$ monsoon depressions and cyclones studied by many authors, most recently by Boos et al. (2017). 

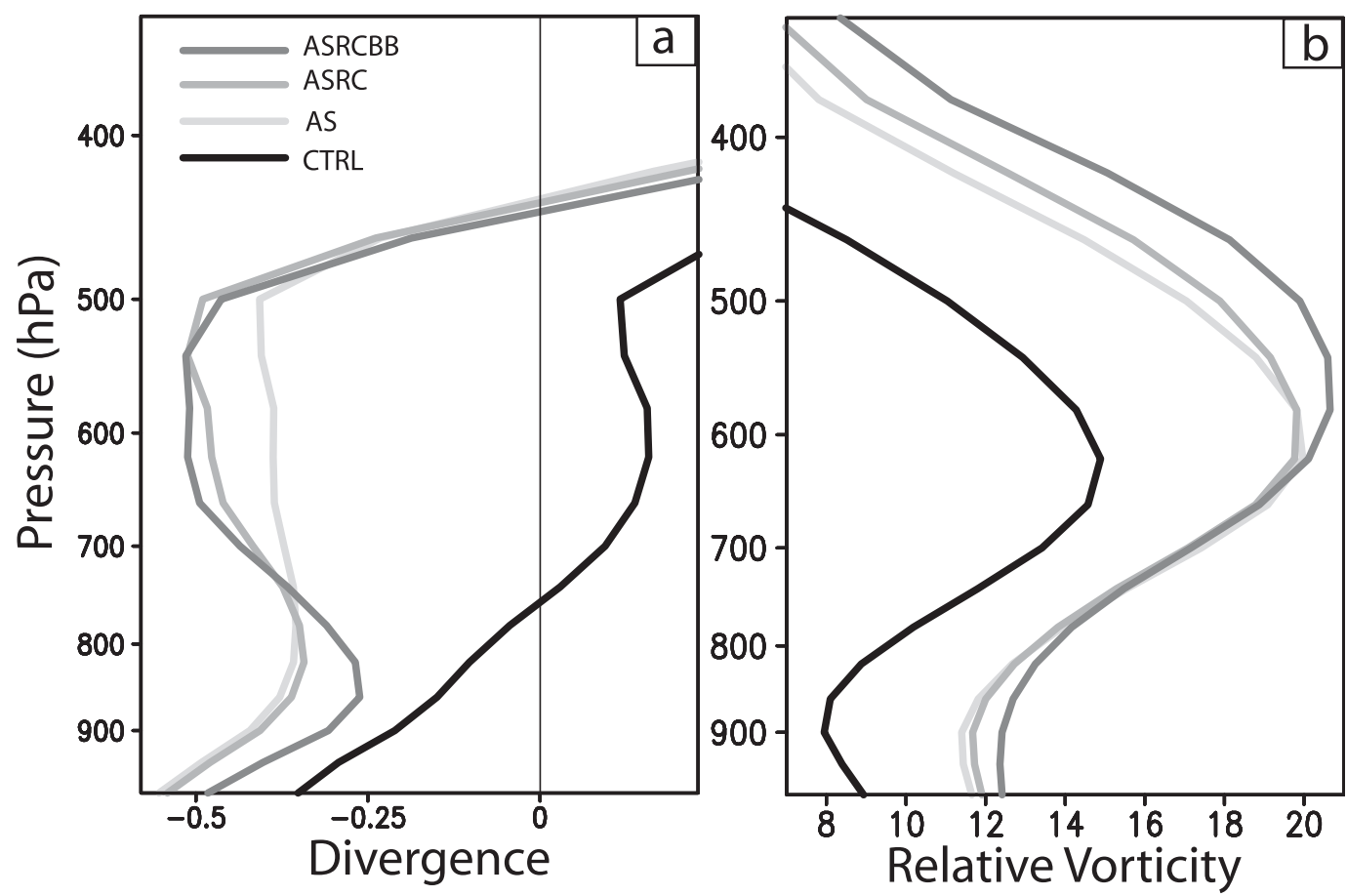

FIG. 17. Vertical profiles of (a) divergence $\left(10^{-6} \mathrm{~s}^{-1}\right)$ and (b) relative vorticity $\left(10^{-6} \mathrm{~s}^{-1}\right)$ averaged over the MTC region for the four experiments (CTRL, AS, ASRC, ASRCBB).

\section{Concluding remarks}

Midlevel cyclogenesis over the northern Arabian Sea had previously been attributed to the export of vorticity from the monsoon heat low (Ramage 1966) or from a dissipating monsoon depression (MK68). These concepts essentially relied on limited data from a single MTC event that occurred during 2-10 July 1963 (MK68). Earlier studies also recognized the importance of latent heat release from cumulus convection during MTC events (e.g., Krishnamurti and Hawkins 1970;
Carr 1977; Mak 1983), although realistic representation of the top heaviness of latent heating over the tropics and monsoon areas was not fully appreciated until more recently (e.g., Houze 1997). The linkage of stratiform and convective heating processes still remains a fundamental challenge for most of the state-of-the-art weather prediction and climate models (Krishnamurti et al. 2010; Mapes et al. 2009). While theoretical investigations have mostly addressed dynamical instability mechanisms of the MTC (e.g., Mak 1975, 1983), a systematic understanding of the MTC from a phenomenological

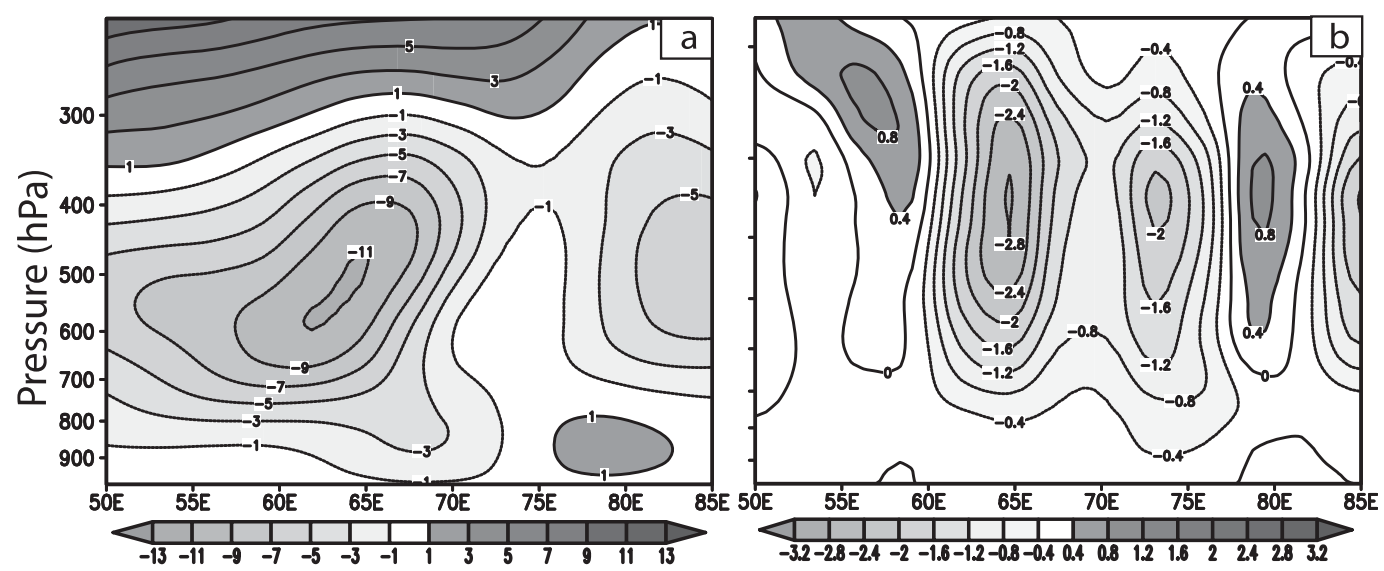

FIG. 18. Height-longitude section of anomalous (a) geopotential height (m) and (b) vertical velocity $\left(\mathrm{Pa} \mathrm{s}^{-1}\right)$ averaged between $15^{\circ}$ and $24^{\circ} \mathrm{N}$. 

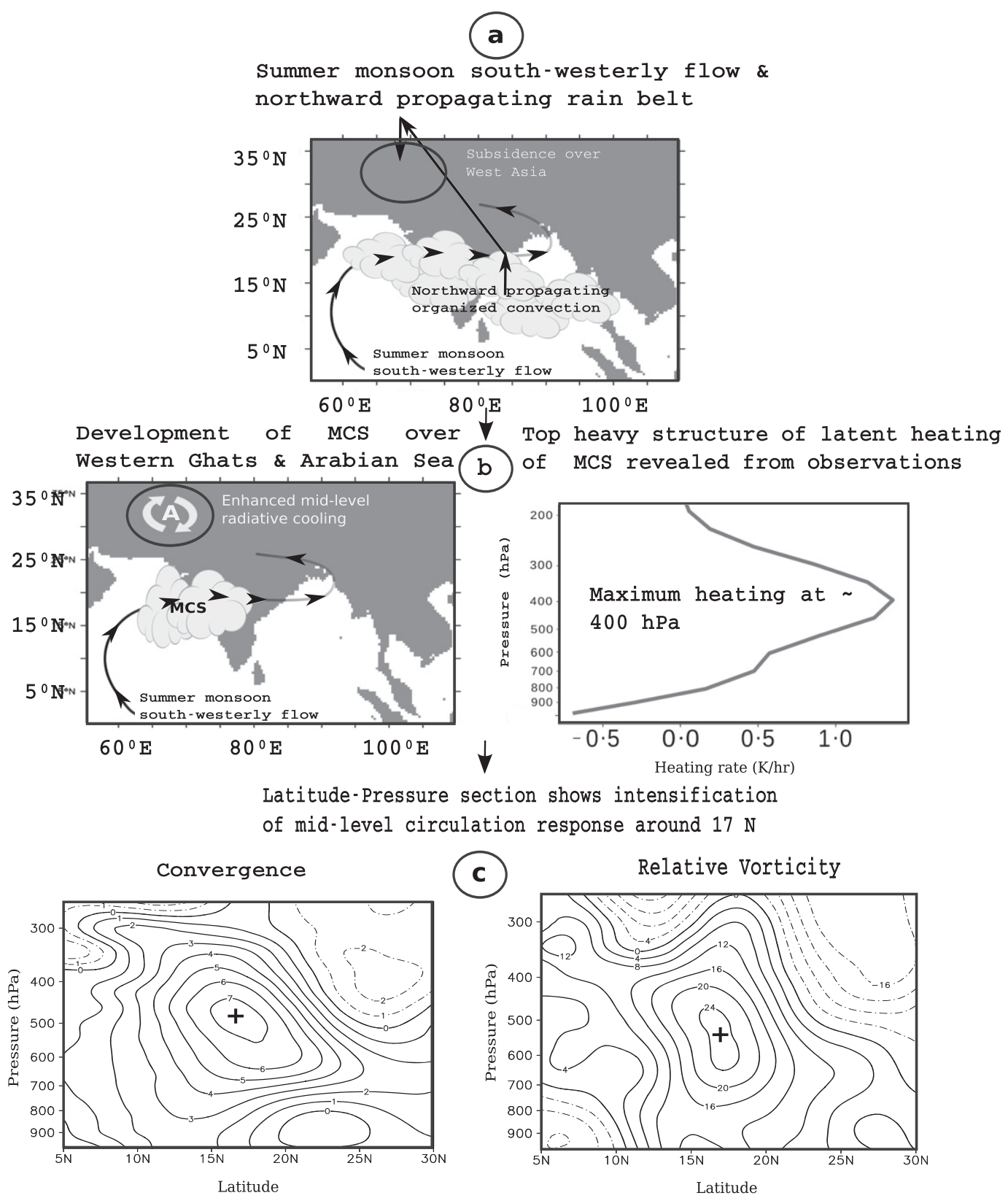

FIG. 19. Schematic depicting conceptual sequence of mechanisms leading to the genesis of the MTC. The vertical gradient of the top-heavy MCS latent heating creates midtropospheric convergence and cyclogenesis as shown by the latitude-pressure sections longitudinally averaged between $60^{\circ}$ and $70^{\circ} \mathrm{E}$ from the ASRC experiment.

perspective (including diabatic effects) is critical to realism and therefore for reliable outlooks of heavy rainfall and floods associated with these monsoon synoptic systems. Toward such an understanding, we performed a composite diagnostic analysis of 20 cases of long-lived, intense, heavily precipitating MTCs over the northern Arabian Sea in the period 1988-2008. In addition, we conducted numerical experiments using a simplified atmospheric GCM forced with prescribed heatings based on observations in order to elucidate a conceptual framework for the genesis of MTC over the northeastern Arabian Sea.

The present analysis reveals that the formation of MTCs over north Arabian Sea is an aspect of the broader monsoon, with dependence on slow northward propagation of summer monsoon rain belts on the subcontinent scale. This rain belt is enriched in mesoscale precipitation systems composed largely of 
stratiform-type precipitation, with top-heavy heating profiles. At the same time, high pressure anomalies over subtropical west Asia are involved, driven by clear-air radiative cooling. About 3 days prior to the formation of MTC, it is seen that an envelope of northwardpropagating summer monsoon convection induces mesoscale convective systems (MCSs) and top-heavy latent heating. The maximum vertical gradient located at midtropospheric levels generates a midtropospheric cyclonic vortex, directly (in the potential vorticity framing), and thereafter through midlevel convergence and stretching (in the associated vorticity viewpoint that explains actual circulations). Results from GCM experiments indicate a nearly fourfold increase in midlevel convergence over the northern Arabian Sea in response to latent heating associated with the precipitating systems, leading to generation of a realistic midlevel cyclonic vortex in the diagnostic model.

Furthermore, the northward-propagating monsoon rain belt includes anomalous subsidence to its north, leading to drying and thus lower-troposphere radiative cooling over the west Asian subtropics. It is seen from the GCM experiments that the circulation response to intensified radiative cooling over west Asia further enhances midlevel northerly anomalies directed from the subtropics into the MTC. However, the simulated impact of this west Asian subtropical cooling is relatively small compared to the convergence forced by the heating estimated from mesoscale precipitation system rainfall. Further, it is seen from the GCM experiments that heating anomalies in westward-moving low pressure systems from BoB, correlated with west coast MTCs and therefore present in our composite, favor expansion of the horizontal scale of MTC so that the midlevel cyclonic circulation extends westward to the Arabian Peninsula. In observations, most of our long-lived ( $\geq 5$ days) heavily precipitating MTCs over northern Arabian Sea are indeed found to be accompanied by such a large-scale enhancement of midtropospheric circulation response with high specific humidity.

The main highlight from this study is the pivotal role of the top-heavy latent heating by stratiform-type mesoscale precipitation systems in driving the formation of midtropospheric cyclonic vorticity. This analysis provides a phenomenological framework for the formation mechanism of MTC, with its multiple diabatic complexities, and its link to the subseasonal-scale variations of larger-scale organized summer monsoon convection. The availability of the three-dimensional latent heating estimates based on precipitation measurements from the TRMM satellite and the primitive equation solver capable of utilizing this heating data in GCM sensitivity experiments are valuable tools of diagnostic interpretation that could fruitfully be extended to many other regions and phenomena.

Acknowledgments. The authors gratefully acknowledge the Director of the Indian Institute of Tropical Meteorology (IITM), Pune, for support. We thank the three anonymous reviewers for providing valuable comments. A. D. C. and R. K. gratefully acknowledge the support of Dr. Shoichi Shige, Kyoto University, for providing support with the SLH $3 \mathrm{H} 25$ dataset. IITM receives financial support from the Ministry of Earth Sciences, Government of India. Financial support for M. V. S. Ramarao is through the ASSAR/ CARIAA project, IIHS, Bengaluru. The model simulations were performed using the high-performance computing (HPC) facility at IITM.

\section{REFERENCES}

Ahmed, F., C. Schumacher, Z. Feng, and S. Hagos, 2016: A retrieval of tropical latent heating using the 3D structure of precipitation features. J. Appl. Meteor. Climatol., 55, 19651982, https://doi.org/10.1175/JAMC-D-15-0038.1.

Bitan, A., and H. Saaroni, 1992: The horizontal and vertical extension of the Persian Gulf pressure trough. Int. J. Climatol., 12, 733-747, https://doi.org/10.1002/joc.3370120706.

Bollasina, M., and S. Nigam, 2011: The summertime heat low over Pakistan/northwestern India: Evolution and origin. Climate Dyn., 37, 957-970, https://doi.org/10.1007/s00382-010-0879-y.

Boos, W. R., J. V. Hurley, and V. S. Murthy, 2015: Adiabatic westward drift of Indian monsoon depressions. Quart. J. Roy. Meteor. Soc., 141, 1035-1048, https://doi.org/10.1002/qj.2454.

— B. E. Mapes, and V. S. Murthy, 2017: Potential vorticity structure and propagation mechanism of Indian monsoon depressions. The Global Monsoon System, C. P. Chang et al., Eds., World Scientific, 187-199.

Bosilovich, M., and Coauthors, 2015: MERRA-2: Initial evaluation of the climate. NASA Tech. Rep. NASA/TM-2015-104606, Vol. 43, 136 pp.

Bourke, W., 1974: A multi-level spectral model. I. Formulation and hemispheric integrations. Mon. Wea. Rev., 102, 687-701, https://doi.org/10.1175/1520-0493(1974)102<0687: AMLSMI $>2.0 . \mathrm{CO} ; 2$.

Brode, R. W., and M.-K. Mak, 1978: On the mechanism of the monsoonal mid-tropospheric cyclone formation. J. Atmos. Sci., 35, 1473-1484, https://doi.org/10.1175/1520-0469(1978) 035<1473:OTMOTM>2.0.CO;2.

Carr, F. H., 1977: Mid-tropospheric cyclones of the summer monsoon. Pure Appl. Geophys. (PAGEOPH), 115, 1383-1412, https://doi.org/10.1007/BF00874415.

Chattopadhyay, R., B. N. Goswami, A. K. Sahai, and K. Fraedrich, 2009: Role of stratiform rainfall in modifying the northward propagation of monsoon intraseasonal oscillation. J. Geophys. Res., 114, D19114, https://doi.org/10.1029/2009JD011869.

Choudhury, A. D., and R. Krishnan, 2011: Dynamical response of the South Asian monsoon trough to latent heating from stratiform and convective precipitation. J. Atmos. Sci., 68 , 1347-1363, https://doi.org/10.1175/2011JAS3705.1.

Das, P. K., and H. S. Bedi, 1981: A numerical model of the monsoon trough. Monsoon Dynamics, J. Lighthill and R. Pearce, Eds., Cambridge University Press, 351-363. 
Dee, D. P., and S. Uppala, 2009: Variational bias correction of satellite radiance data in the ERA-Interim reanalysis. Quart. J. Roy. Meteor. Soc., 135, 1830-1841, https://doi.org/10.1002/ qj. 493 .

_, and Coauthors, 2011: The ERA-Interim reanalysis: Configuration and performance of the data assimilation system. Quart. J. Roy. Meteor. Soc., 137, 553-597, https://doi.org/ 10.1002/qj.828.

Duchon, C. E., 1979: Lanczos filtering in one and two dimensions. J. Appl. Meteor., 18, 1016-1022, https://doi.org/10.1175/15200450(1979)018<1016:LFIOAT > 2.0.CO;2.

Goswami, B. N., 2005: South Asian monsoon. Intraseasonal Variability of the Atmosphere-Ocean Climate System, W. K. M. Lau and D. E. Waliser, Eds., Springer, 19-61.

Hartmann, D. L., and M. L. Michelsen, 1989: Intraseasonal periodicities in Indian rainfall. J. Atmos. Sci., 46, 28382862, https://doi.org/10.1175/1520-0469(1989)046<2838: IPIIR $>2.0 . \mathrm{CO} ; 2$.

—- H. H. Hendon, and R. A. Houze Jr., 1984: Some implications of the mesoscale circulations in tropical cloud clusters for large-scale dynamics and climate. J. Atmos. Sci., 41, 113-121, https://doi.org/10.1175/1520-0469(1984)041<0113: SIOTMC $>2.0 . \mathrm{CO} ; 2$.

Hoskins, B. J., and M. J. Rodwell, 1995: A model of the Asian summer monsoon. Part I: The global scale. J. Atmos. Sci., 52, 1329-1340, https://doi.org/10.1175/1520-0469(1995)052<1329: AMOTAS $>2.0 . \mathrm{CO} ; 2$.

Houze, R. A., Jr., 1997: Stratiform precipitation in regions of convection: A meteorological paradox? Bull. Amer. Meteor. Soc., 78, 2179-2196, https://doi.org/10.1175/1520-0477 (1997)078<2179:SPIROC $>2.0$.CO;2.

- 2004: Mesoscale convective systems. Rev. Geophys., 42, RG4003, https://doi.org/10.1029/2004RG000150.

Huffman, G. J., and Coauthors, 1997: The Global Precipitation Climatology Project (GPCP) combined precipitation dataset. Bull. Amer. Meteor. Soc., 78, 5-20, https://doi.org/10.1175/ 1520-0477(1997)078<0005:TGPCPG > 2.0.CO;2.

— tion Analysis (TMPA): Quasi-global, multiyear, combinedsensor precipitation estimates at fine scales. J. Hydrometeor., 8, 38-55, https://doi.org/10.1175/JHM560.1.

Hunt, K. M. R., A. G. Turner, P. M. Inness, D. E. Parker, and R. C. Levine, 2016: On the structure and dynamics of Indian monsoon depressions. Mon. Wea. Rev., 144, 3391-3416, https://doi.org/10.1175/MWR-D-15-0138.1.

Hurley, J. V., and W. R. Boos, 2015: A global climatology of monsoon low pressure systems. Quart. J. Roy. Meteor. Soc., 141, 1049-1064, https://doi.org/10.1002/qj.2447.

Jayanthi, N., M. Rajeevan, A. K. Srivastava, S. Devi, S. K. Roy Bhowmik, and H. R. Hatwar, 2006: Monsoon 2006: A Report. Synoptic Meteor., No. 4/2006, Indian Meteorological Department, $103 \mathrm{pp}$.

Kodama, Y.-M., M. Katsumata, S. Mori, S. Satoh, Y. Hirose, and H. Ueda, 2009: Climatology of warm rain and associated latent heating derived from TRMM-PR observations. J. Climate, 22, 4908-4929, https://doi.org/10.1175/2009JCLI2575.1.

Konwar, M., S. K. Das, S. M. Deshpande, K. Chakravarty, and B. N. Goswami, 2014: Microphysics of clouds and rain over the western Ghat. J. Geophys. Res. Atmos., 119, 6140-6159, https://doi.org/10.1002/2014JD021606.

Krishnamurthy, V., and J. Shukla, 2000: Intraseasonal and interannual variability of rainfall over India. J. Climate, 13, 4366-4377, https:// doi.org/10.1175/1520-0442(2000)013<0001:IAIVOR>2.0.CO;2. $\longrightarrow$, and — 2007: Intraseasonal and seasonally persisting patterns of Indian monsoon rainfall. J. Climate, 20, 3-20, https:// doi.org/10.1175/JCLI3981.1.

$\longrightarrow$, and — 2008: Seasonal persistence and propagation of intraseasonal patterns over the Indian monsoon region. Climate Dyn., 30, 353-369, https://doi.org/10.1007/s00382-007-0300-7.

Krishnamurti, T. N., and R. Hawkins, 1970: Mid-tropospheric cyclones of the southwest monsoon. J. Appl. Meteor., 9, 442-458, https://doi.org/10.1175/1520-0450(1970)009<0442: MTCOTS $>2.0 . \mathrm{CO} ; 2$.

, and D. Subrahmanyam, 1982: The 30-50 day mode at $850 \mathrm{mb}$ during MONEX. J. Atmos. Sci., 39, 2088-2095, https://doi.org/ 10.1175/1520-0469(1982)039<2088:TDMAMD>2.0.CO;2.

_ A. Chakraborty, and A. Mishra, 2010: Improving multimodel forecasts of the vertical distribution of heating using the TRMM profiles. J. Climate, 23, 1079-1094, https://doi.org/ 10.1175/2009JCLI2878.1.

Krishnan, R., and S. V. Kasture, 1996: Modulation of low frequency intraseasonal oscillations of northern summer monsoon by El Nino and Southern Oscillation (ENSO). Meteor. Atmos. Phys., 60, 237-257, https://doi.org/10.1007/BF01042187.

_ C. Zhang, and M. Sugi, 2000: Dynamics of breaks in the Indian summer monsoon. J. Atmos. Sci., 57, 1354-1372, https:// doi.org/10.1175/1520-0469(2000)057<1354:DOBITI>2.0.CO;2. , D. C. Ayantika, V. Kumar, and S. Pokhrel, 2011: The longlived monsoon depressions of 2006 and their linkage with the Indian Ocean dipole. Int. J. Climatol., 31, 1334-1352, https:// doi.org/10.1002/joc.2156.

Kumar, S., A. Hazra, and B. N. Goswami, 2014: Role of interaction between dynamics, hermodynamics and cloud microphysics on summer monsoon precipitating clouds over the Myanmar coast and the Western Ghats. Climate Dyn., 43, 911-924, https://doi.org/10.1007/s00382-013-1909-3.

Kumar, V., and T. N. Krishnamurti, 2016: Mesoscale modeling for the rapid movement of monsoonal isochrones. Atmos. Sci. Lett., 17, 78-86, https://doi.org/10.1002/asl.617.

Lau, K.-M., and P. Chan, 1986: Aspects of the 40-50 day oscillation during the northern summer as inferred from outgoing longwave radiation. Mon. Wea. Rev., 114, 1354-1367, https://doi.org/ 10.1175/1520-0493(1986)114<1354:AOTDOD>2.0.CO;2.

Mak, M.-K., 1975: The monsoonal mid-tropospheric cyclogenesis. J. Atmos. Sci., 32, 2246-2253, https://doi.org/10.1175/15200469(1975)032<2246:TMMTC > 2.0.CO;2.

_ 1983: A moist baroclinic model for monsoonal mid-tropospheric cyclogenesis. J. Atmos. Sci., 40, 1154-1162, https://doi.org/ 10.1175/1520-0469(1983)040<1154:AMBMFM>2.0.CO;2.

Mapes, B. E., 1993: Gregarious tropical convection. J. Atmos. Sci., 50, 2026-2037, https://doi.org/10.1175/1520-0469(1993) 050<2026:GTC > 2.0.CO;2.

_ 2011: Heaviest precipitation events, 1998-2007: A near-global survey. The Global Monsoon System: Research and Forecast, World Scientific,15-22.

_ , and R. A. Houze Jr., 1995: Diabatic divergence profiles in western Pacific mesoscale convective systems. J. Atmos. Sci., 52, 1807-1828, https://doi.org/10.1175/1520-0469(1995) 052<1807:DDPIWP $>2.0$.CO;2.

_ J. Bacmeister, M. Khairoutdinov, C. Hannay, and M. Zhao, 2009: Virtual field campaigns on deep tropical convection in climate models. J. Climate, 22, 244-257, https://doi.org/ 10.1175/2008JCLI2203.1.

Matilla, B., and B. E. Mapes, 2018: An atlas of tropical extremes. Tropical Extremes: Natural Variability and Trends, V. Vuruputur et al., Eds., Elsevier Press, in press. 
Mazumdar, A., R. R. Lele, and S. S. Devi, 2007: Monsoon season (June to September 2006). Mausam, 58, 409-458.

$\longrightarrow$ M. Khole, and S. S. Devi, 2008: Monsoon season (June to September 2007). Mausam, 59, 381-430.

,$- \longrightarrow$, and — 2009: Monsoon season (June to September 2008). Mausam, 60, 379-426.

Miller, F. R., and R. N. Keshavamurthy, 1968: Structure of an Arabian Sea Summer Monsoon System. Meteor. Monogr., Vol. 1, East-West Center Press, 94 pp.

Pai, D., L. Sridhar, M. Badwaik, and M. Rajeevan, 2015: Analysis of the daily rainfall events over India using a new long period (1901-2010) high resolution $\left(0.25^{\circ} \times 0.25^{\circ}\right)$ gridded rainfall data set. Climate Dyn., 45, 755-776, https://doi.org/10.1007/s00382-014-2307-1.

Pokhrel, S., and D. R. Sikka, 2013: Variability of the TRMM-PR total and convective and stratiform rain fractions over the Indian region during the summer monsoon. Climate Dyn., 41, 21-44, https://doi.org/10.1007/s00382-012-1502-1.

Ramage, C., 1966: The summer atmospheric circulation over the Arabian Sea. J. Atmos. Sci., 23, 144-150, https://doi.org/10.1175/ 1520-0469(1966)023<0144:TSACOT>2.0.CO;2.

Rodwell, M. J., and B. J. Hoskins, 1996: Monsoons and the dynamics of deserts. Quart. J. Roy. Meteor. Soc., 122, 1385-1404, https://doi.org/10.1002/qj.49712253408.

Romatschke, U., and R. A. Houze Jr., 2011: Characteristics of precipitating convective systems in the South Asian monsoon. J. Hydrometeor., 12, 3-26, https://doi.org/10.1175/2010JHM1289.1.

Routray, A., U. C. Mohanty, D. Niyogi, S. Rizvi, and K. K. Osuri, 2010: Simulation of heavy rainfall events over Indian monsoon region using WRF-3DVAR data assimilation system. Meteor. Atmos. Phys., 106, 107-125, https://doi.org/10.1007/ s00703-009-0054-3.

Saaroni, H., B. Ziv, I. Osetinsky, and P. Alpert, 2010: Factors governing the interannual variation and the long-term trend of the $850 \mathrm{hPa}$ temperature over Israel. Quart. J. Roy. Meteor. Soc., 136, 305-318, https://doi.org/10.1002/qj.580.

Schumacher, C., and R. A. Houze Jr., 2003: Stratiform rain in the tropics as seen by the TRMM Precipitation Radar. J. Climate, 16, 1739-1756, https://doi.org/10.1175/1520-0442(2003)016<1739: SRITTA $>2.0 . C O ; 2$.

,-- , and I. Kraucunas, 2004: The tropical dynamical response to latent heating estimates derived from the TRMM Precipitation Radar. J. Atmos. Sci., 61, 1341-1358, https://doi.org/ 10.1175/1520-0469(2004)061<1341:TTDRTL>2.0.CO;2.

—, M. H. Zhang, and P. E. Ciesielski, 2007: Heating structures of the TRMM field campaigns. J. Atmos. Sci., 64, 2593-2610, https://doi.org/10.1175/JAS3938.1.

Shige, S., and C. D. Kummerow, 2016: Precipitation-top heights of heavy orographic rainfall in the Asian monsoon region. $J$. Atmos. Sci., 73, 3009-3024, https://doi.org/10.1175/JAS-D-15-0271.1.

—, Y. N. Takayabu, W.-K. Tao, and D. E. Johnson, 2004: Spectral retrieval of latent heating profiles from TRMM PR data. Part I: Development of a model-based algorithm. J. Appl. Meteor., 43, 1095-1113, https://doi.org/10.1175/1520-0450(2004) 043<1095:SROLHP $>2.0$. CO;2.

,,,-- , and C.-L. Shie, 2007: Spectral retrieval of latent heating profiles from TRMM PR data. Part II: Algorithm improvement and heating estimates over tropical ocean regions. J. Appl. Meteor. Climatol., 46, 1098-1124, https:// doi.org/10.1175/JAM2510.1.
,-- , S. Kida, W.-K. Tao, X. Zeng, and T. L'Ecuyer, 2009: Spectral retrieved of latent heating profiles from TRMM PR data. Part VI: Comparisons of lookup tables from two- and three-dimensional simulations. J. Climate, 22, 5577-5594, https://doi.org/10.1175/2009JCLI2919.1.

_- Y. Nakano, and M. K. Yamamoto, 2017: Role of orography, diurnal cycle, and intraseasonal oscillation in summer monsoon rainfall over Western Ghats and Myanmar coast. J. Climate, 30, 9365-9381, https://doi.org/10.1175/JCLI-D-16-0858.1.

Sikka, D. R., and S. Gadgil, 1980: On the maximum cloud zone and the ITCZ over Indian longitudes during the southwest monsoon. Mon. Wea. Rev., 108, 1840-1853, https://doi.org/10.1175/ 1520-0493(1980)108<1840:OTMCZA > 2.0.CO;2.

Singh, S. V., R. H. Kripalani, and D. Sikka, 1992: Interannual variability of the Madden-Julian oscillations in Indian summer monsoon rainfall. J. Climate, 5, 973-978, https://doi.org/ 10.1175/1520-0442(1992)005<0973:IVOTMJ > 2.0.CO;2.

Stano, G., T. N. Krishnamurti, T. V. Kumar, and A. Chakraborty, 2002: Hydrometeor structure of a composite monsoon depression using the TRMM radar. Tellus, 54A, 370-381, https:// doi.org/10.1034/j.1600-0870.2002.01330.x.

Sundaram, S., R. Krishnan, A. Dey, and P. Swapna, 2010: Dynamics of intensification of the boreal summer monsoon flow during IOD events. Meteor. Atmos. Phys., 107, 17-31, https:// doi.org/10.1007/s00703-010-0066-z.

Tao, W.-K., and Coauthors, 2001: Retrieved vertical profiles of latent heat release using TRMM rainfall products for February 1998. J. Appl. Meteor., 40, 957-982, https://doi.org/10.1175/ 1520-0450(2001)040<0957:RVPOLH >2.0.CO;2.

_ - S. Lang, X. Zeng, S. Shige, and Y. Takayabu, 2010: Relating convective and stratiform rain to latent heating. J. Climate, $\mathbf{2 3}$, 1874-1893, https://doi.org/10.1175/2009JCLI3278.1.

Tyrlis, E., J. Lelieveld, and B. Steil, 2013: The summer circulation over the eastern Mediterranean and the Middle East: Influence of the South Asian monsoon. Climate Dyn., 40, 11031123, https://doi.org/10.1007/s00382-012-1528-4.

Utsav, B., S. M. Deshpande, S. K. Das, and G. Pandithurai, 2017: Statistical characteristics of convective clouds over the Western Ghats derived from weather radar observations. J. Geophys. Res. Atmos., 122, 10 050-10 076, https://doi.org/10.1002/2016JD026183.

Virts, K. S., and R. A. Houze Jr., 2016: Seasonal and intraseasonal variability of mesoscale convective systems over the South Asian monsoon region. J. Atmos. Sci., 73, 4753-4774, https:/ doi.org/10.1175/JAS-D-16-0022.1.

Wang, B., 2005: Theory. Intraseasonal Variability in the AtmosphereOcean Climate System, W. K.-M. Lau and D. E. Waliser, Eds., Springer, 307-360.

Wu, G., Y. Liu, X. Zhu, W. Li, R. Ren, A. Duan, and X. Liang, 2009: Multi-scale forcing and the formation of subtropical desert and monsoon. Ann. Geophys., 27, 3631-3644, https:/ doi.org/10.5194/angeo-27-3631-2009.

Yasunari, T., 1979: Cloudiness fluctuations associated with the Northern Hemisphere summer monsoon. J. Meteor. Soc. Japan, 57, 227-242, https://doi.org/10.2151/jmsj1965.57.3_227.

_ 1980: A quasi-stationary appearance of 30 to 40 day period in the cloudiness fluctuations during the summer monsoon over India. J. Meteor. Soc. Japan, 58, 225-229, https://doi.org/ 10.2151/jmsj1965.58.3_225. 